\title{
Ergonomic evaluation of block lifting tools on biomechanical stresses to masons
}

\author{
Meng Han \\ West Virginia University
}

Follow this and additional works at: https://researchrepository.wvu.edu/etd

\section{Recommended Citation}

Han, Meng, "Ergonomic evaluation of block lifting tools on biomechanical stresses to masons" (2010). Graduate Theses, Dissertations, and Problem Reports. 4602.

https://researchrepository.wvu.edu/etd/4602

This Thesis is protected by copyright and/or related rights. It has been brought to you by the The Research Repository @ WVU with permission from the rights-holder(s). You are free to use this Thesis in any way that is permitted by the copyright and related rights legislation that applies to your use. For other uses you must obtain permission from the rights-holder(s) directly, unless additional rights are indicated by a Creative Commons license in the record and/ or on the work itself. This Thesis has been accepted for inclusion in WVU Graduate Theses, Dissertations, and Problem Reports collection by an authorized administrator of The Research Repository @ WVU. For more information, please contact researchrepository@mail.wvu.edu. 


\title{
Ergonomic Evaluation of Block Lifting Tools on Biomechanical Stresses to Masons
}

\author{
Meng Han \\ Thesis submitted to the \\ College of Engineering and Mineral Resources \\ at West Virginia University \\ in partial fulfillment of the requirements \\ for the degree of \\ Master of Science \\ in \\ Industrial Engineering
}

Kevin Rider, Ph.D., Chair

Majid Jaraiedi, Ph.D.

Ashish Nimbarte, Ph.D.

Department of Industrial and Management Systems Engineering

Morgantown, West Virginia

2010

Keywords: Lifting Tool, Masonry, Ergonomics, Biomechanical Stresses

Copyright 2010 Meng Han 


\section{ABSTRACT \\ Ergonomic Evaluation of Block Lifting Tools on Biomechanical Stresses to Masons}

\section{Meng Han}

Masonry has very high incidence rate of all construction trades for injuries with lost workdays due to overexertion involving lifting in the USA. An increasingly frequent masonry task is the construction of retaining walls for landscaping purposes, whereas retaining wall blocks typically weigh 80 pounds or more, and are oddly shaped with poor hand coupling. Due to the extreme weight of the blocks and poor hand coupling, workers are often required to use awkward postures and jerking motions during the lift and place of the block. As a result of these challenges associated with manipulating these blocks by hand, tools have been designed to assist the mason during the lifting task. Unfortunately, these lifting tools have not been shown to actually reduce the risk of an injury, and even the expected benefits from their use are speculative. It is essential that the design and use of these tools are evaluated to ensure that these workers are not being placed at an increased risk of injury. The efficacy of a block lifting tool (Versa-Lok Lifter) for reducing biomechanical strain on the worker has been evaluated based on the data of joint stresses and population-based strength provided by University of Michigan's 3D Static Strength Prediction Program (3DSSPP). The study shows that the Versa-Lok Lifter can 
reduce the low back compression during the lifting. However using this tool may increase the risks for some major joints of human body at high levels. 


\section{ACKNOWLEDGEMENTS}

I would like to thank my advisor, Dr. Kevin Rider, for his great guidance, for giving me the opportunity to work on this project, which could not have been written without his encouragement and support.

I am also thankful to Dr. Majid Jaraiedi and Dr. Ashish Nimbarte for serving on my committee, and for their insightful ideas and assistance in preparing this thesis. 


\section{TABLE OF CONTENTS}

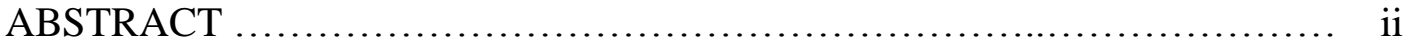

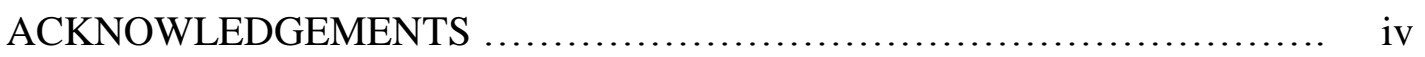

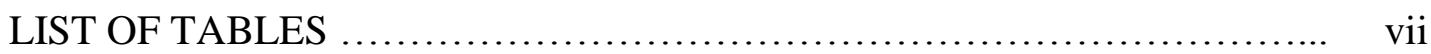

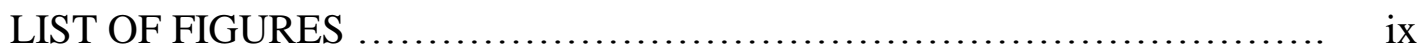

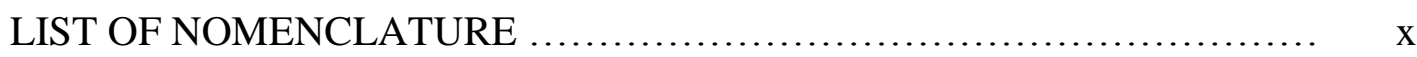

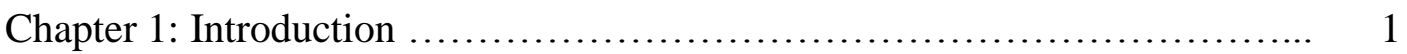

Chapter 2: Review of Relevant Literature and Past Research ............... 5

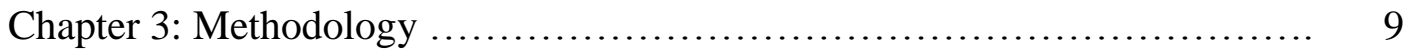

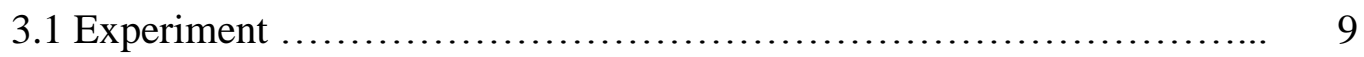

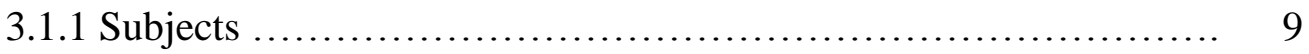

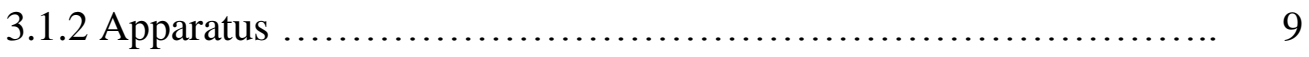

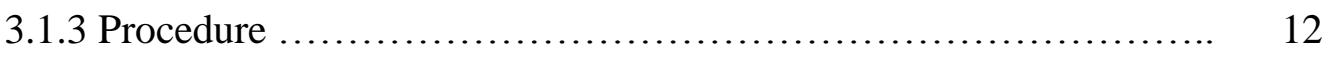

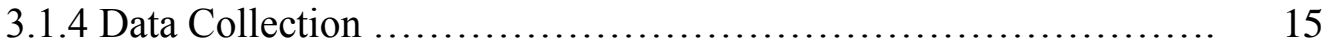

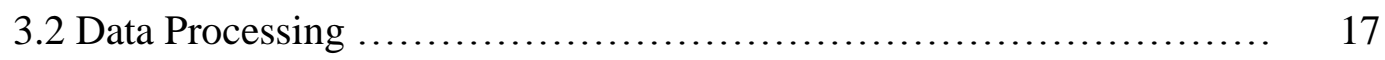

3.3 Data Analysis ............................................... 17

3.3.1 Low Back Pressure Compression .......................... 17

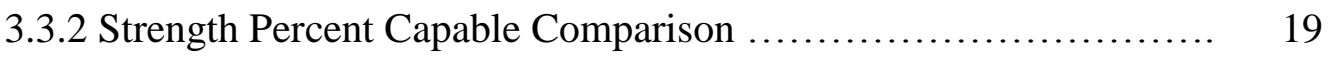

3.3.3 NIOSH Lifting Equation $\ldots \ldots \ldots \ldots \ldots \ldots \ldots \ldots \ldots \ldots \ldots \ldots \ldots \ldots, 20$

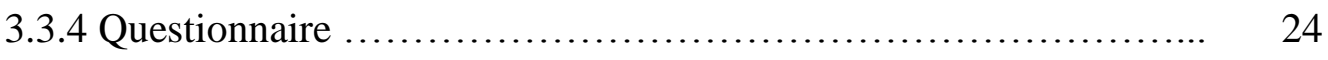

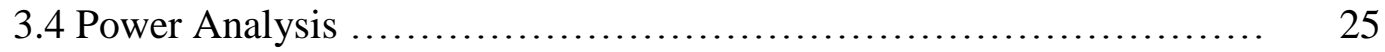


3.4.1 Determination of the Number of Subjects .................... 25

3.4.2 Determination of the Number of Replicates .................... 26

Chapter 4: Results ............................................. 28

4.1 Low Back Pressure Compression $\ldots \ldots \ldots \ldots \ldots \ldots \ldots \ldots \ldots \ldots \ldots \ldots . . \ldots \ldots$

4.2 Strength Percent Capable Comparison ........................... 30

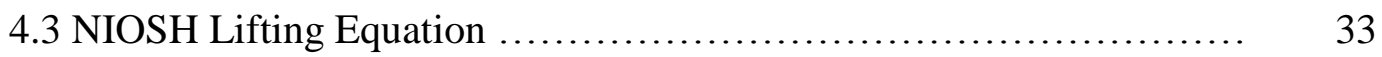

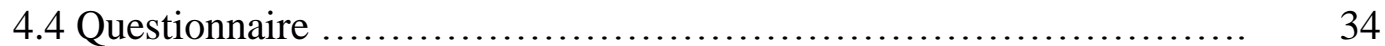

Chapter 5: Discussion and Conclusion ............................. 36

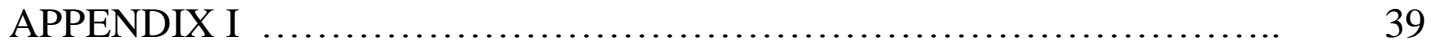

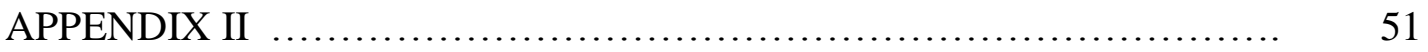

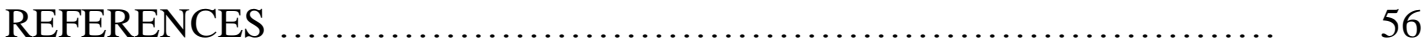




\section{LIST OF TABLES}

Table 3.1 Necessary definitions in applying the NIOSH lifting equation .............. 21

Table 3.2 Power value for different subjects ................................. 26

Table 3.3 OC curve parameters for fix model ................................ 26

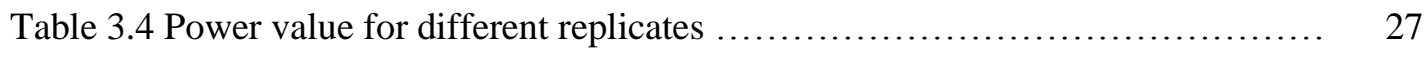

Table 4.1 Tool factor effects for different levels for Model $2 \ldots \ldots \ldots \ldots \ldots \ldots \ldots \ldots \ldots . \quad 30$

Table $4.295 \%$ confidence interval of strength capabilities for seven major joints at the beginning

Table $4.395 \%$ confidence interval of strength capabilities for all major joints at the end

Table 4.4 Major joints of the strength capability which is below $25 \% \ldots \ldots \ldots \ldots \ldots \ldots . . . . . .33$

Table 4.5 LI value between two lifting method and four lifting heights ............. 34

Table A1.1 Average angle and low back compression for subject 1 with tool lifting

Table A1.2 Average angle and low back compression for subject 1 with manual lifting

Table A1.3 Average angle and low back compression for subject 2 with tool lifting

Table A1.4 Average angle and low back compression for subject 2 with manual lifting

Table A1.5 Average angle and low back compression for subject 3 with tool lifting 
Table A1.6 Average angle and low back compression for subject 3 with manual lifting

Table A1.7 Average angle and low back compression for subject 4 with tool lifting

Table A1.8 Average angle and low back compression for subject 4 with manual lifting

Table A1.9 Average angle and low back compression for subject 5 with tool lifting

Table A1.10 Average angle and low back compression for subject 5 with manual lifting

Table A1.11 Average angle and low back compression for subject 6 with tool lifting

Table A1.12 Average angle and low back compression for subject 6 with manual lifting

Table A2.1 Horizontal Multiplier ................................................ 51

Table A2.2 Vertical Multiplier .................................................. 51

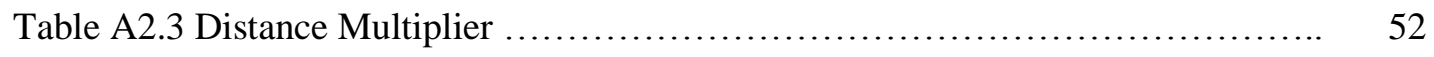

Table A2.4 Asymmetric Multiplier ............................................. 52

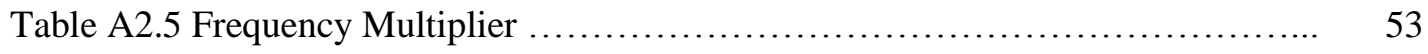

Table A2.6 Hand-to-Container Coupling Classification ............................ 53

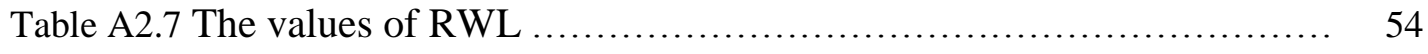

Table A2.8 The values of all the six task variables for NIOSH lifting equation.... 55

Table A2.9 The values of all the six coefficients for NIOSH lifting equation...... 55 


\section{LIST OF FIGURES}

Figure 3.1 Versa-Lok lifter in block .................................... 10

Figure 3.2 Individually lifting block by using hands ........................ 14

Figure 3.3 Lifting block by using Versa-Lifter ............................. 14

Figure 3.4 Side-by-side comparison of recorded human motion (left) and strength analysis (right)

Figure 3.5 Results status window ......................................... $\quad 20$

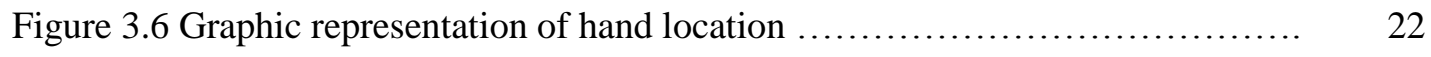

Figure 3.7 Graphic representation of angle of asymmetry (A) ................... 23

Figure 4.1 ANOVA tables for model 1 and model $2 \ldots \ldots \ldots \ldots \ldots \ldots \ldots \ldots \ldots \ldots . \ldots \ldots$

Figure 4.2 Difficulty among using different lifting methods and different height ..... 35 


\section{LIST OF NOMENCLATURE}

$\tau_{\mathbf{i}} \quad$ The effect of lifting heights which are $1.5 \mathrm{ft}, 2.5 \mathrm{ft}, 3.5 \mathrm{ft}$ and $4.5 \mathrm{ft}(\mathrm{i}=1,2,3,4)$

$\beta_{\mathrm{j}} \quad$ The effect of lifting method. Two levels of this factor represent lifting either with tool or without tool $(j=1,2)$

$\gamma_{\mathrm{k}}$ The effect of subjects, $\mathrm{k}=1,2,3,4,5,6$.

$(\tau \beta)_{\mathrm{ij}} \quad$ The interaction effect between lifting ways and lifting height.

$\varepsilon_{i j k l} \quad$ Random error.

$n \quad$ Number of replications at each combination

$\mathrm{yB} \quad$ The low pack pressure for beginning position of the lifting

$\mathrm{yE} \quad$ The low pack pressure for ending position of the lifting

$\sigma_{\gamma}{ }^{2} \quad$ Variance component of $\gamma$ factor

$\sigma^{2} \quad$ Variance component of random error factor

RWL Recommended weight limit

LC Load Constant, 23kg (Metric) or 51lb (U.S. Customary)

HM Horizontal Multiplier

VM Vertical Multiplier

FM Frequency Multiplier

DM Distance Multiplier

AM Asymmetry Multiplier

CM Hand-to-Container Coupling Multiplier

LI Lifting Index

MSBL Mean square of blocks

MSE Mean square error

$\alpha \quad$ Probability of Type I error

$\beta \quad$ Probability of Type II error

$\lambda \quad$ Parameter used in Operating Characteristic Curves for the random effects model.

c Number of Subjects 
V1 Numerator degree of freedom used in Operating Characteristic Curves for Fixed Effects Model

V2 Denominator degree of freedom used in Operating Characteristic Curves for Fixed Effects Model

a Number of different lifting heights

b Number of different ways of tool using

n Number of replications

$\Phi \quad$ Parameters used in Operating Characteristic Curves for the fixed effects model

$y_{\cdot j} \cdot \quad$ Average low back compression for certain way of tool using

y.... Average low back compression for all trails

$y_{i j}$. $\quad$ Average low back compression for combination of certain lifting height and way of toll using

$y_{i} \ldots \quad$ Average low back compression for certain lifting height 


\section{Chapter 1: Introduction}

In the United States, masonry has very high incidence rate of all construction trades for injuries with lost workdays due to overexertion involving lifting (D. Anton et al. 2005). An increasingly frequent masonry task is the construction of retaining walls for landscaping purposes, whereas retaining wall blocks typically weigh 80 pounds or more, and are oddly shaped with poor hand coupling. This results in overexertion, the most common cause for low back pain, from which as many as $50 \%$ of workers are away from work for greater than 30 days, and resulting in costs exceeding $\$ 100$ billion annually. Therefore, there is a critical need to evaluate the biomechanical strain experienced by this understudied population of workers, so that effective interventions can be developed.

Construction of retaining wall systems requires the repetitive lifting of large concrete blocks that have been causing low back injuries at an alarming rate within the construction industry. These "hardscape" operations can be performed using heavy machinery, but the terrain often prevents feasible access of these machines, requiring masons to handle these blocks themselves. Due to the extreme weight of the blocks and poor hand coupling, workers are often required to use awkward postures and jerking motions during the lift and place of the block. As a result of these challenges associated with manipulating these blocks by hand, tools have been designed to assist the mason during the lifting task. Unfortunately, these lifting tools have not been shown to actually 
reduce the risk of an injury, and even the expected benefits from their use are speculative. It is essential that the design and use of these tools are evaluated to ensure that these workers are not being placed at an increased risk of injury.

With respect to these operations, injuries to the lower back are both the frequent and costly to a company, but other injuries commonly occur, such as trauma. Without use of a lifting tool, the hands are required to directly contact the course concrete of the heavy block, which can result in the lacerations, or pinching of fingers. Furthermore, in order to adequately grasp the block, it is often tilted to one side, so that the fingers or a foot can get underneath for support in order to obtain a secure grasp. This awkward posture may hurt your fingers and foot if the block falls. If this block is located on the ground, then the mason has to assume a posture that lowers the hands completely to the ground, thus increasing the risk of a lower back injury. Due to the mechanical disadvantage resulting from the heavily stooped or squatted posture, lifting these blocks from the ground commonly often results in dynamic jerking motions, which may increase the compressive loading on the spine by $50 \%$. After lifting the block, the placement of the block on the intended location on the wall also can result in the same hazards as previously mentioned, effectively doubling the risk of these injuries occurring.

Lifting tools are designed to provide a mechanical advantage and improved coupling for the hands. One of the most common block lifting devices used in construction of residential retaining walls will be evaluated: the Versa-Lifter. There is no documented 
evidence that this tool reduces the risk of an injury, it may even increase the risk. To its advantage, this tool typically attaches to the top of the block, using weight-loaded friction to couple the block and tool, and reduces the amount of torso flexion required since the workers' hands only lower enough to grasp the handle, and not the bottom of the block. Additionally, the improved coupling reduces the propensity for pinching and lacerations from direct contact with the block. Conversely, the lifting tool may create additional hazards that do not otherwise exist, or are at least less likely to occur, during direct manipulation of the blocks. And the tool may also affect the strength capabilities of some major joints of the body. In the cases where the tool is not sufficiently inserted into the blocks, these blocks can fall or swing onto the feet and legs of the lifter during the task. Moreover, the lifting techniques employed while using this tool vary, are not readily available from, or stipulated by, the manufacturer, and are only constrained by the workers' own ability to physically complete the task. An additional concern regarding the use of the block lifting tool is that the improved hand coupling may lead workers to have a lower perception of the risks, which may lead to use of less safe behaviors and lifting techniques. In cases where the perception of risk is significantly lower than the actual risk of an injury, workers may become less cautious, more easily distracted, and are much more likely to injure themselves. It is essential that these tools and the associated lifting techniques be evaluated in order to quantify the biomechanical stresses that result from using these tools to perform block lifting tasks, and subsequently assess the risk associated with these tasks. 
Our central hypothesis is that without the results obtained from objective evaluations, companies cannot know if they are providing a workplace free from recognized hazards. To answer this question, a combined field and laboratory study will be performed to establish the effects of this lifting device on work demands and on energetic and biomechanical workload in a real world setting. The proposed study will seek to evaluate effectiveness of this retaining wall block lifter to allow masons to perform these tasks with nominal risk, and optimize the hand lifting tool.

The principal objective of this research is to evaluate the efficacy of a block lifting tool (Versa-Lok Lifter) for reducing biomechanical strain on the worker. Six experienced male masons performed lifting tasks, they individually used the Versa-Lok lifter or hand lifting the block from the ground to four different heights $(1.5 \mathrm{ft}, 2.5 \mathrm{ft}, 3.5 \mathrm{ft}, 4.5 \mathrm{ft})$ and then lowered it back to the ground. The lifting tasks are very similar to those performed by experienced masons every day. Based on the data of joint stresses and populationbased strength provided by University of Michigan's 3D Static Strength Prediction Program (3DSSPP), Lifting Index (LI) from NIOSH Lifting Equation, and subjects' feelings, we can determine the advantages and limitations for this tool. 


\section{Chapter 2: Review of Relevant Literature and Past Research}

Masonry workers have been performing their work the same way for many years, and experience the second highest back injury rate with the construction industry. Few ergonomic interventions have been introduced from which masons can benefit, and heavy lifting remains one of a mason's most physically demanding tasks.

Laying blocks involves a high physical workload and is associated with low back disorders among masons, studies have investigated the effect of manual materials handling jobs for several decades. Hamilton and Chase (1969) found that at a certain productivity, people prefer to handle higher weights at lower frequencies than lower weights at higher frequencies. And previous research showed that motion segment damage may arise, both from a single maximal compressive force and cyclic loading protocols at submaximal force level (Brinckmann et al., 1988; Hansson et al., 1987; Liu et al., 1983 ). In 1996, Looze et al. concluded that it was not clear that a reduction in brick weight implied a reduction of the spinal load, and the incorporation of the time aspects of the load was of importance in risk evaluations. This shows the importance of time of exposure to the load in addition to the load's weight. Anton et al. (2005) also reported that compared with the light-weight blocks, muscle activity was not routinely greater when handling standard-weight blocks. Despite the minimal effect reported for block weight, the results of the study clearly demonstrate the adverse effects of working 
with the arms elevated at or above shoulder level. Actually, the knowledge of the increased risk of injury for elevated arm work was first found by using Rapid upper-limb assessment (RULA) (McAtamney and Corlett, 1993). Several laboratory investigations also have reported the positive relationship between work with the arm elevated at or above shoulder height and increased muscle activity, shorter duration and greater fatigue (e.g. Haslegrave et al. 1997, Gary et al. 2002). It implies that, mechanical lifting equipment or devices to adjust working height should be implemented to substantially lower the risk of low back injury. Additionally, in 2008, Van Der Molen et al. found that block weight, varying between 11 and $16 \mathrm{~kg}$, had no effect on production for the number of blocks placed, total weight handled, duration and frequency of tasks and activities, energetic workload and cumulative spinal load over a full work day. But in our research, the blocks are much heavier, so this conclusion may be not appropriate for us.

In order to minimize injuries, masons often have a lifting tool available to assist these block lifting tasks; however empirical evidence does not currently exist to support that these lifting devices reduce strain on the workers' lower back.

Since the block weight is too heavy, if we could reduce the work load, that would be best way to reduce the risks of an injury. And the most simple way to reduce the weight is team lifting, the literature associated with team lifting also offers some interesting concerns. Karwowski, and Mital (1986) reported that the lifting capacity of the twoperson team was less than the sum of individual isometric and isokinetic lifting strengths. 
Karwowski (1988) confirmed through psychophysical criteria that teams were willing to lift less than the sum of the individuals' maximum acceptable lifts. However Johnson and Lewis (1989) have reported that during both team lifting and carrying, subjects were willing to lift weights that were greater than the sum of the individuals' acceptable weights. It is interesting to note that many of these studies intentionally mismatched subject anthropometry and found decreased team lifting capacity, while Johnson and Lewis stated they matched subjects for height. They were also the only ones who found a decrease of the lifting weight capacity in individual-lifting. Marras et al. (1999) compared 3-D lumbar spinal loads between a range of symmetrical and asymmetrical lifting conditions, and found that lifts performed under asymmetrical conditions incurred significantly lower lateral torque and shear force during individual lifting than during team lifting. Conversely, during symmetrical lifting tasks the maximum sagittal plane torque and compression force at L5/S1 were both found to be significantly greater during individual lifts than during team lifts. Spine compression is greater with one-person carrying, whereas lateral shear is greater with two-person carrying. In 2002, Dennis et al. similarly found that maximum and average L4/L5 torque and compression force in the sagittal plane were significantly greater during individual lifts than during team lifts. Since the subjects in that experiment were not instructed to use a particular lifting technique, it is concluded that subjects naturally exploit the opportunity to decrease spinal loads by exerting a pulling force on the load and keeping the load closer to the lumbar spine in team lifting compared to individual lifting. 
Results from the present study will provide currently unavailable information regarding the risk of masonry lifting tasks associated with the Versa-Lifter, and may serve as a branching point for the development and design of lifting devices for use in all facets of manual construction tasks. Developing interventions such as these may help reduce a mason's risk of developing low back disorders without any major changes in their work habits. 


\section{Chapter 3: Methodology}

\subsection{Experiment:}

\subsubsection{Subjects:}

Six experienced male masons performed 5 replications of lifting tasks. West Virginia University (WVU) Institutional Review Boards for Protection of Human Research Subjects (IRB) ensure that this human subject research at WVU is appropriate and conforms to federal regulations (IRB \#21995). Determinations of the number of subjects and replicates were based on power approach, as explained in section 3.3. The lifting tasks are similar to those performed by experienced masons every day. Since lifting 75pound blocks is known to potentially cause injury or aggravate existing conditions, subjects with previous back injuries resulting in surgery or back injuries within the last six months were not permitted to participate in the study.

\subsubsection{Apparatus:}

VERSA-LOK BLOCK LIFTER.

The Versa-Lifter was developed by Versa-Lok $\odot$ to be used in conjunction with the Versa-Lok@ Retaining Wall System@ $\odot$. This device consists of a handle attached to a horizontal bar which has a prong on each end that extends downward into the retaining wall block. The Versa-Lifter is designed to make lifting and placing the blocks easier. 
The two prongs on the lifter are placed into the holes in the Versa-Lok block (shown in Figure 3.1), where the action of lifting the handle secures the lifter.

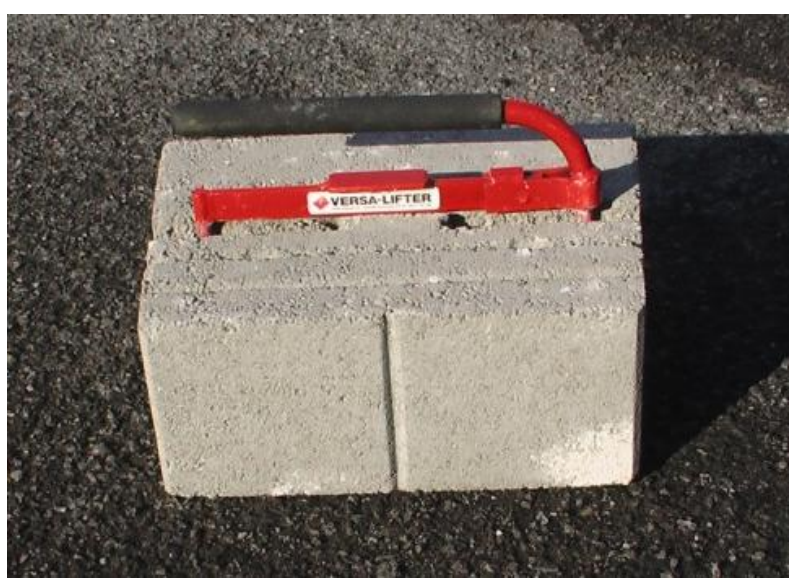

Figure 3.1 Versa-Lifter in block

VICON NEXUS® MOTION MEASUREMENT SYSTEM.

VICON systems have been used to track and analyze movement for over 20 years. They

offer the researchers highly accurate motion-based measurements according to independent tests. The combination of high-speed video cameras, and light weight retroreflective markers now offer accuracy to within $0.1 \mathrm{~mm}$. The small markers easily attach to the subjects and do not require wires or heavy batteries, which can make movements more challenging. Through the use of VICON, we record the 3D positions of all the markers, providing data to reconstruct a biomechanical model of the participants. 
UNIVERSITY OF MICHIGAN'S 3D STATIC STRENGTH PREDICATION PROGRAM.

The University of Michigan's 3D Static Strength Prediction Program (3DSSPP) is based on over 30 years of research at the Center for Ergonomics regarding the biomechanical and static strength capabilities of the employee in relation to the physical demands of the work environment (3DSSPP, Background). The 3DSSPP software computes static strength requirements for tasks such as lifts, carrying, pushes, and pulls. The model then predicts the percentage of people who have the strength to perform the described job, the spinal compression forces, and data comparisons to NIOSH guidelines. The main function of 3DSSPP is to evaluate the physical demands for a prescribed job, proposing new workplace designs, or redesigning an existing one. It was developed with the assumption that effects of acceleration and momentum are negligible, and is most proper to be used in analyzing "slow" motion of movements with heavy materials handling jobs. Then normal tasks can be broken into a sequence of static postures and then be evaluated as necessary.

\section{MINITAB SOFTWARE.}

Minitab is a powerful, easy-to-use, statistical software package that provides a wide range of basic and advanced data analysis capabilities. In this research, we used it to do all the statistical analysis. 
ENERGY EXPENDITURE PREDICTION PROGRAM.

The Energy Expenditure Prediction Program ${ }^{\mathrm{TM}}$ (EEPP) is a software tool to estimate energy expenditure rates for materials handling tasks to help assure worker safety and health. It predicts metabolic energy expenditure rates by summing up the energy requirements of small, well-defined work tasks that comprise the entire job. The energy expenditures of the tasks are calculated by using prediction equations derived from empirical data. The informations for compute these energy requirements include: gender, body weight, distance moved, frequency, task posture, and the time needed to perform the tasks. We used EEPP to calculate the energy expenditure of the lifting tasks in this research, in order to make sure it does not exceed the $3.5 \mathrm{kcal} / \mathrm{min}$ action limit guideline for an average 8-hour day set by the National Institute for Occupational Safety and Health (NIOSH).

\subsubsection{Procedure:}

The lifting tasks were performed both manually and with the lifting tool.

1. Six experienced male masons were recruited for this study. All the tasks for each subject were exactly the same, and the order were randomized.

2. A consent form was provided describing any known or foreseeable risks and potential discomforts to the subjects. 
3. Anthropometric measurements were recorded (e.g., body mass, height, link lengths) in order to maintain the highest degree of fidelity while analyzing the data.

4. One sensor configuration served as a control condition in which subjects wore a set of light-weight retro-reflective markers. With the control sensor suite, we had subjects wear standard shorts and sleeveless shirts made of lightweight cotton as well.

5. Before signing the consent form, subjects received a verbal introduction of the lifting tasks. They were introduced to every cycle that they would be asked to do, and they could ask questions about the apparatus or procedures.

6. During the experiment, subjects were instructed to either perform the task manually (shown in Figure 3.2) or with Versa-Lifter (shown in Figure 3.3), lifting the block from the ground and placing to one of four heights $(1.5 \mathrm{ft}, 2.5 \mathrm{ft}, 3.5 \mathrm{ft}$, 4.5ft).Then lowered the block back to the ground in preparation for the next lift. 


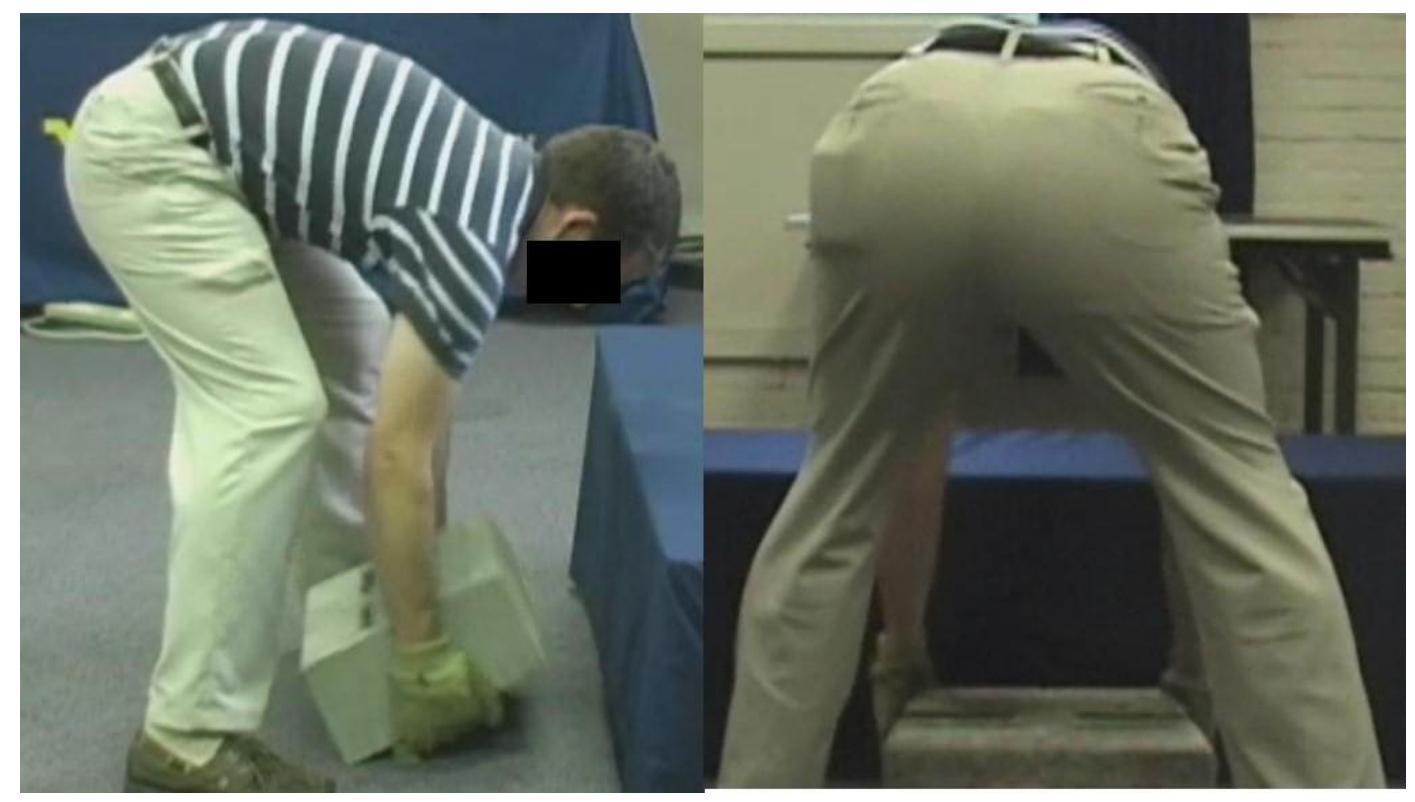

Figure 3.2 Individually lifting block by using hands

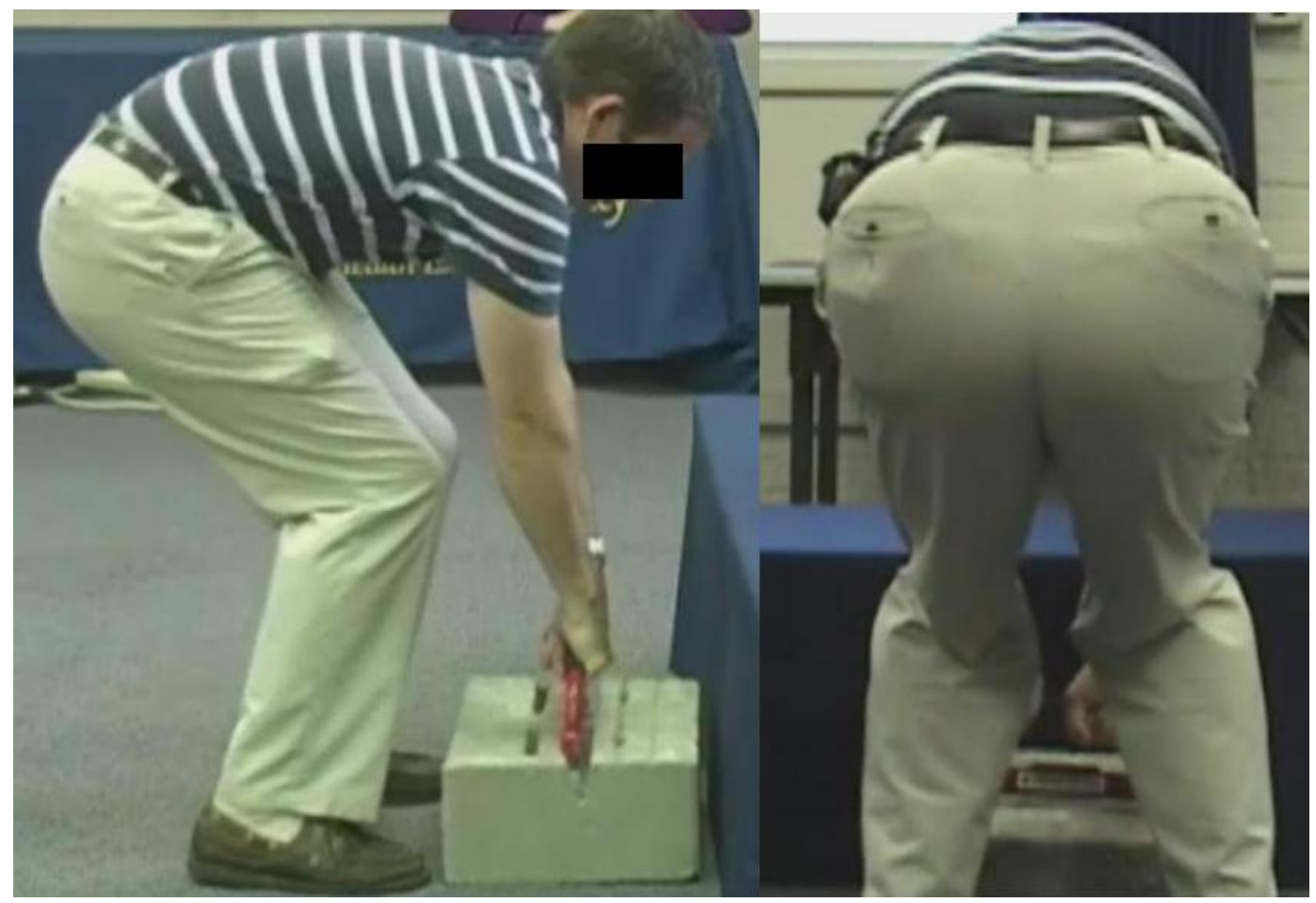

Figure 3.3 Lifting block by using Versa-Lifter 
Both the lifting methods and the heights were randomly assigned to each subject. Participants lifted and placed the retaining wall block at four different heights, and then had a period to rest before the next series of lifts. Approximately 1.5 minutes was required to perform the block of four lifts. The 6 subjects were randomly assigned to the task at the beginning of the whole experiment, and then they continually did the task as the same order. When one subject performed a series of lifts, the other 5 subjects took a rest, which would provide each subject 7.5 minutes rest time between each 1.5 minutes series of lifts.

7. After each lift, the subject would be asked to rate the difficulty of the lift on a scale from 1 (Easily finish the task) to 10 (Barely finish the task).

8. In order to observe adaptation differences during the lifting tasks, 5 replications were required.

\subsubsection{Data Collection:}

The VICON motion capture system was used to track the motion of the participants. Through use of high speed video cameras and markers, this system collected the coordinates (X, Y, Z axis) of each marker's position, in order to reconstruct a 3D biomechanical model. After capturing the subjects' movements, the VICON Nexus software is used reconstruct the $3 \mathrm{D}$ position of the markers with plug in gait marker set, 
from which a digital skeleton can be constructed. Then based on it, we used 3DSSPP software to calculate the compression of the lower back, and the population-based estimates of strength capability of seven major joints: wrist, elbow, shoulder, torso, hip, knee, and ankle. The right portion of Figure 3.4 shows an example of the 3DSSPP interface and information provided, whereas the left part shows the human motion capture interface in VICON.

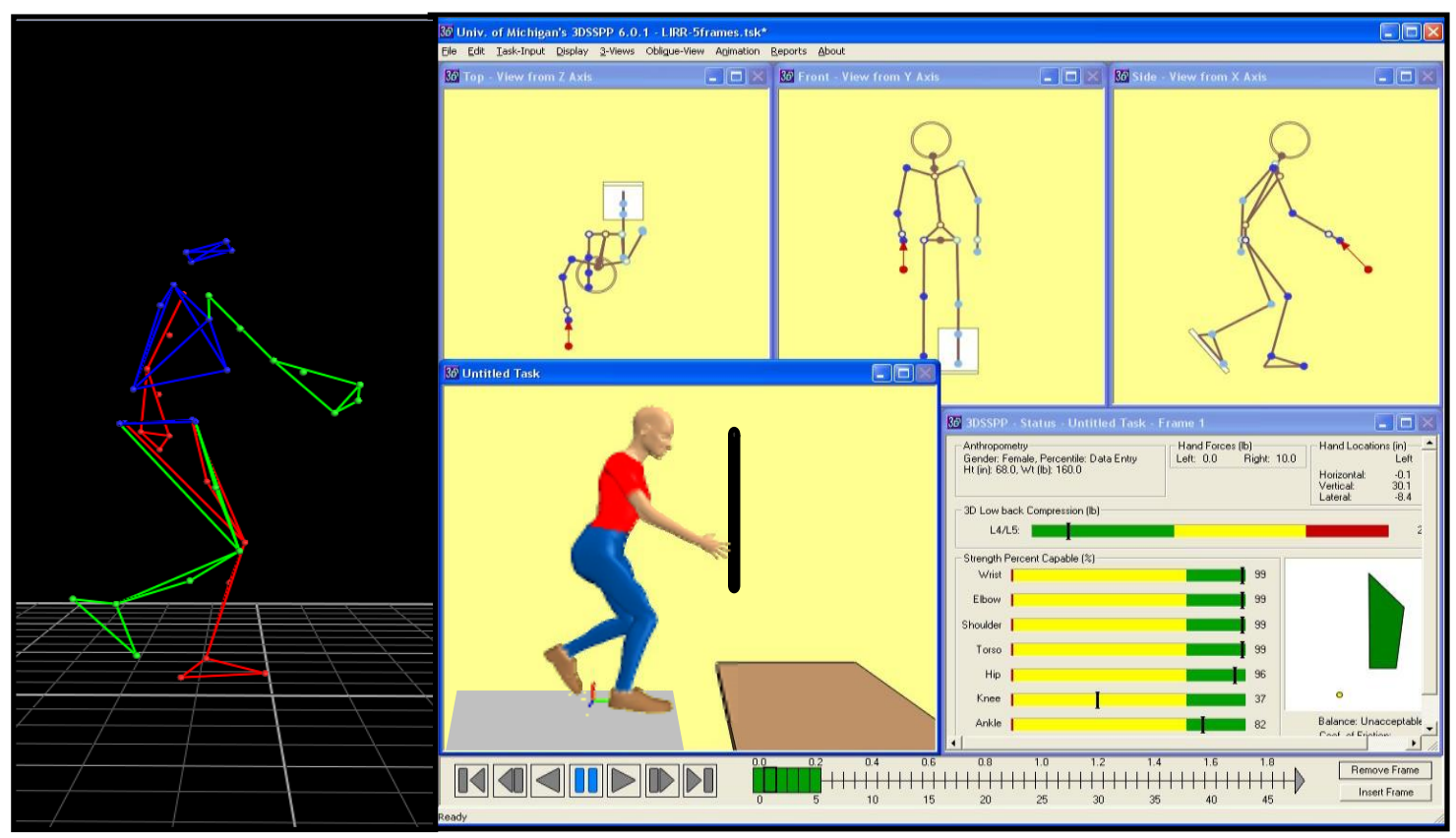

Figure 3.4 Side-by-side comparison of reconstructed VICON data (left) and the 3DSSPP strength analysis (right) 


\subsection{Data processing:}

The 3DSSPP does not yet allow for importing VICON data. So after we got the coordinates (X, Y, Z axis) of each marker from VICON, these data were converted into global joint angles by using Pythagorean theorem and trigonometric functions. Then we put these angles into 3DSSPP, which calculated the subjects' low back compression and strength capabilities. The average value of all the angles we put into 3DSSPP, and low back compression see APPENDIX I.

\subsection{Data Analysis:}

Since significant control of an object is required at both the origin and the destination of a lift, the worker must apply a significant upward force to accelerate and decelerate the object (NIOSH et al. 1994). Pursuant to the NIOSH Work Practices Guide, 3D low back compression and joint strengths were calculated at both the origin and the destination of the lift.

\subsubsection{Low Back Pressure Compression:}

In this research, the lifting tool was evaluated on whether or not the use of it reduces workers' low back compression. Besides, different lifting height and subjects may have varying affect on subject's low back compression. Since the beginning and ending

position of the lift can only be evaluated respectively, two statistical models were built as follows 


\section{Model 1:}

$$
y B_{i j k l}=\mu+\tau_{i}+\beta_{j}+\gamma_{k}+(\tau \beta)_{i j}+\epsilon_{i j k l} \quad\left\{\begin{array}{l}
i=1, \ldots, \mathrm{a} \\
j=1, \ldots, b \\
k=1, \ldots, c \\
l=1, \ldots, n
\end{array}\right.
$$

\section{Model 2:}

$$
y E_{i j k l}=\mu+\tau_{i}+\beta_{j}+\gamma_{k}+(\tau \beta)_{i j}+\epsilon_{i j k l} \quad\left\{\begin{array}{c}
i=1, \ldots, a \\
j=1, \ldots, b \\
k=1, \ldots, c \\
l=1, \ldots, n
\end{array}\right.
$$

- $\tau_{\mathbf{i}}$ are the effect of lifting heights which are $1.5 \mathrm{ft}, 2.5 \mathrm{ft}, 3.5 \mathrm{ft}$ and $4.5 \mathrm{ft}$. Then $\mathrm{i}=1$, $2,3,4$.

- $\quad \beta_{\mathrm{j}}$ are the effect of lifting method. Two levels of this factor represent lifting either with tool or without tool. Then $\mathrm{j}=1,2$.

- $\gamma_{\mathrm{k}}$ are the effect of subjects, $\mathrm{k}=1,2,3,4,5,6$.

- $(\tau \beta)_{\mathrm{ij}}$ is the interaction effect between lifting ways and lifting height.

- $\varepsilon_{i j k l}$ is a random error, 1 represents number of replications at each combination which will be determined in 3.3.2.

- $\mathrm{yB}$ represents the low pack pressure for beginning position of the lifting and $\mathrm{yE}$ represents the low pack pressure for ending position of the lifting.

Lifting heights $\left(\tau_{\mathrm{i}}\right)$, lifting ways $\left(\beta_{\mathrm{j}}\right)$ and interaction effects $\left(\tau \beta_{\mathrm{ij}}\right)$ are treated as fixed effects. It is assumed that $\sum \tau_{i}=0, \sum \beta_{j}=0$ and $\sum \sum \tau \beta_{i j}=0$. Subjects $\left(\gamma_{\mathrm{k}}\right)$ is treated 
as a random effect and it is a $\operatorname{NID}\left(0, \sigma_{\gamma}{ }^{2}\right)$ random variable. Random error $\varepsilon_{i j k l}$ follows $\operatorname{NID}\left(0, \sigma^{2}\right)$.

Two ANOVA tables were provided for two different models. Therefore, the appropriate $F$ tests were applied on testing the means of the fixed factor effects are equal, such as Ho: $\tau_{i}=0$, Ho: $\beta_{j}=0$ and Ho: $\tau \beta_{i j}=0$. Also the appropriate $F$ tests were applied on testing the variance of the random factor equal to zero, such as Ho: $\sigma_{\gamma}{ }^{2}=0$. In this study, the Type I error $\alpha=0.05$ and Power of the test which equals to 0.90 were chosen for the hypothesis test and sample size determination in 3.3 .

For fixed factors, if the null hypothesis was rejected, the factors effects will be estimated. For instance, $\beta_{1}$ and $\beta_{2}$ will be estimated to show the low back pressure difference if the test shows the lifting ways do have effects.

\subsubsection{Strength Percent Capable Comparison:}

The Strength Percent Capable box from 3DSSPP lists a summary of the strength analysis for the major joints strengths. The red potion of the graph indicates that the percent of the population with sufficient strength to perform the task is below $25 \%$, depicting an unacceptable strength requirement. Since the subjects are all strong and professional masons, the yellow and green potion of the graph indicates that the percent of the 
population with sufficient strength to perform the task is above $25 \%$, depicting an acceptable strength requirement, as shown in Figure 3.5.

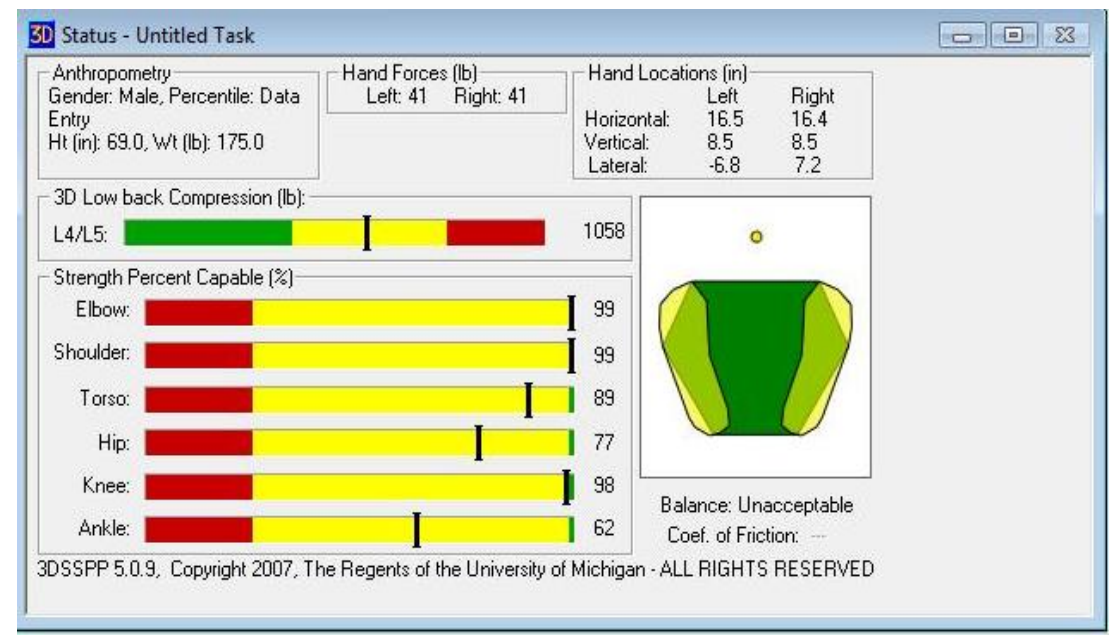

Figure 3.5 Results status window

In order to show the lifting tool's advantage and limits, we used statistical method to analysis the percentage of strength capable.

\subsubsection{NIOSH Lifting Equation:}

$$
R W L=L C \times H M \times V M \times D M \times A M \times F M \times C M
$$

Where,

- LC: $23 \mathrm{~kg}$ (Metric) or $511 \mathrm{~b}$ (U.S. Customary).

- HM, VM, FM, DM, AM, CM: See Table A.1-A.6 in Appendix II. 
Calculating the RWL is based on a multiplicative model that provides a weighting for each of the six task variables. The weightings are expressed as coefficients that serve to decrease the load constant, which represents the maximum recommended load weight to be lifted under ideal conditions.

The Recommended Weight Limit (RWL) is the principal product of the NIOSH lifting equation. The RWL is defined for a specific set of task conditions as the weight of the load that $90 \%$ of the healthy workers could perform over a substantial period of time (e.g., up to 8 hours) without an increased risk of developing lifting-related low back pain. Table 3.1 is a list of brief definitions which are useful in applying the NIOSH lifting equation.

Table 3.1 Necessary definitions in applying the NIOSH lifting equation

\begin{tabular}{|l|l|}
\hline Horizontal Location (H) & $\begin{array}{l}\text { Distance of the hands away from the mid- } \\
\text { point between the ankles, in inches or } \\
\text { centimeters (Measure at the origin and } \\
\text { destination of lift). See Figure 3.6. }\end{array}$ \\
\hline Vertical Location (V) & $\begin{array}{l}\text { Distance of the hands above the floor, in } \\
\text { inches or centimeters (Measure at the origin } \\
\text { and destination of lift). }\end{array}$ \\
\hline Vertical Travel Distance (D) & $\begin{array}{l}\text { Absolute value of the difference between the } \\
\text { vertical heights at the destination and origin } \\
\text { of the lift, in inches or centimeters. }\end{array}$ \\
\hline Asymmetry Angle (A) & $\begin{array}{l}\text { Angular measure of how far the object is } \\
\text { displaced from the front (mid-sagittal plane) } \\
\text { of the worker's body at the beginning or } \\
\text { ending of the lift, in degrees (measure at the } \\
\text { origin and destination of lift). See Figure } \\
3.7 .\end{array}$ \\
\hline Lifting Frequency (F) & $\begin{array}{l}\text { Average number of lifts per minute over a } \\
15 \text { minute period. }\end{array}$ \\
\hline
\end{tabular}




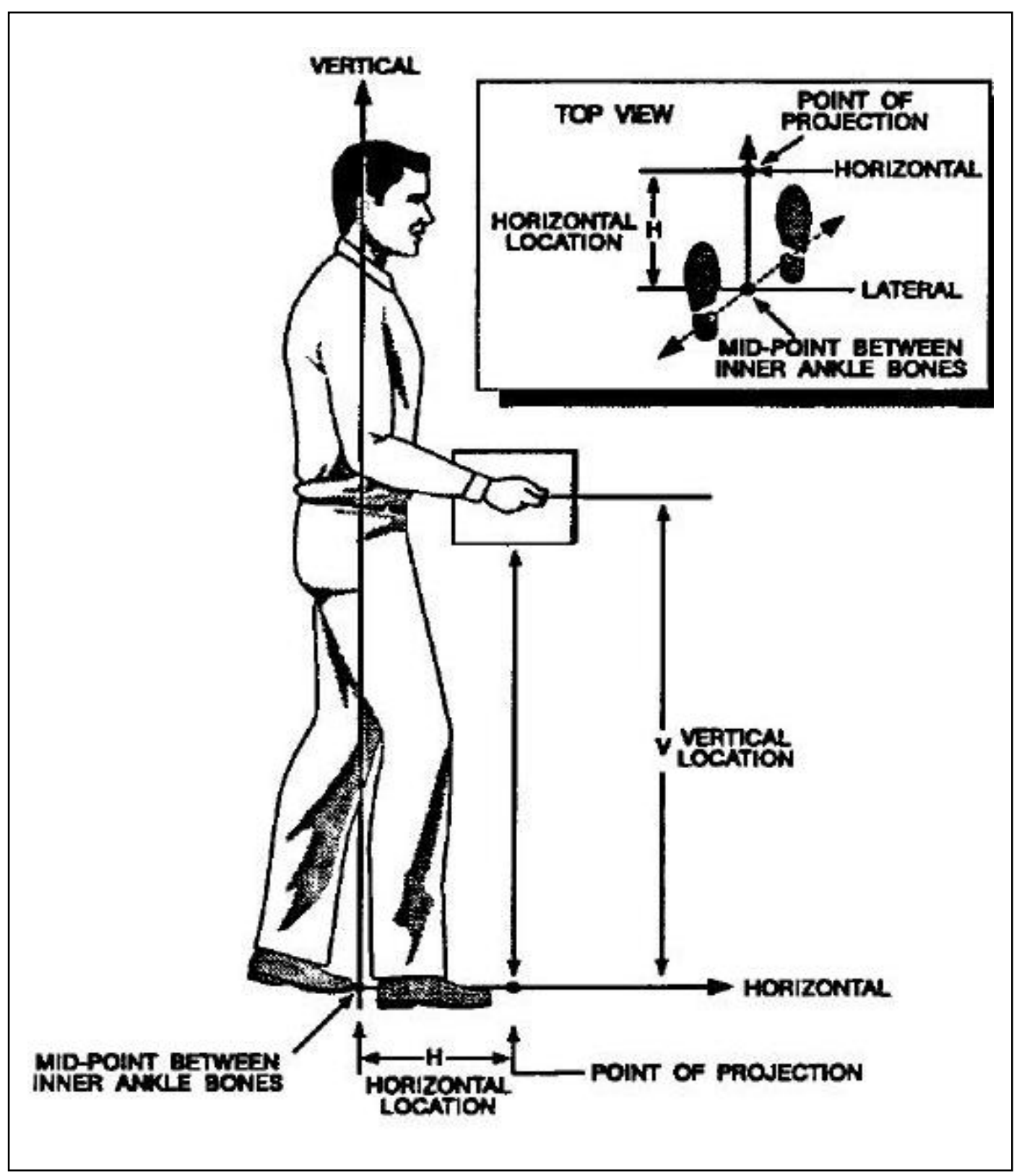

Figure 3.6 Graphic representation of hand location 


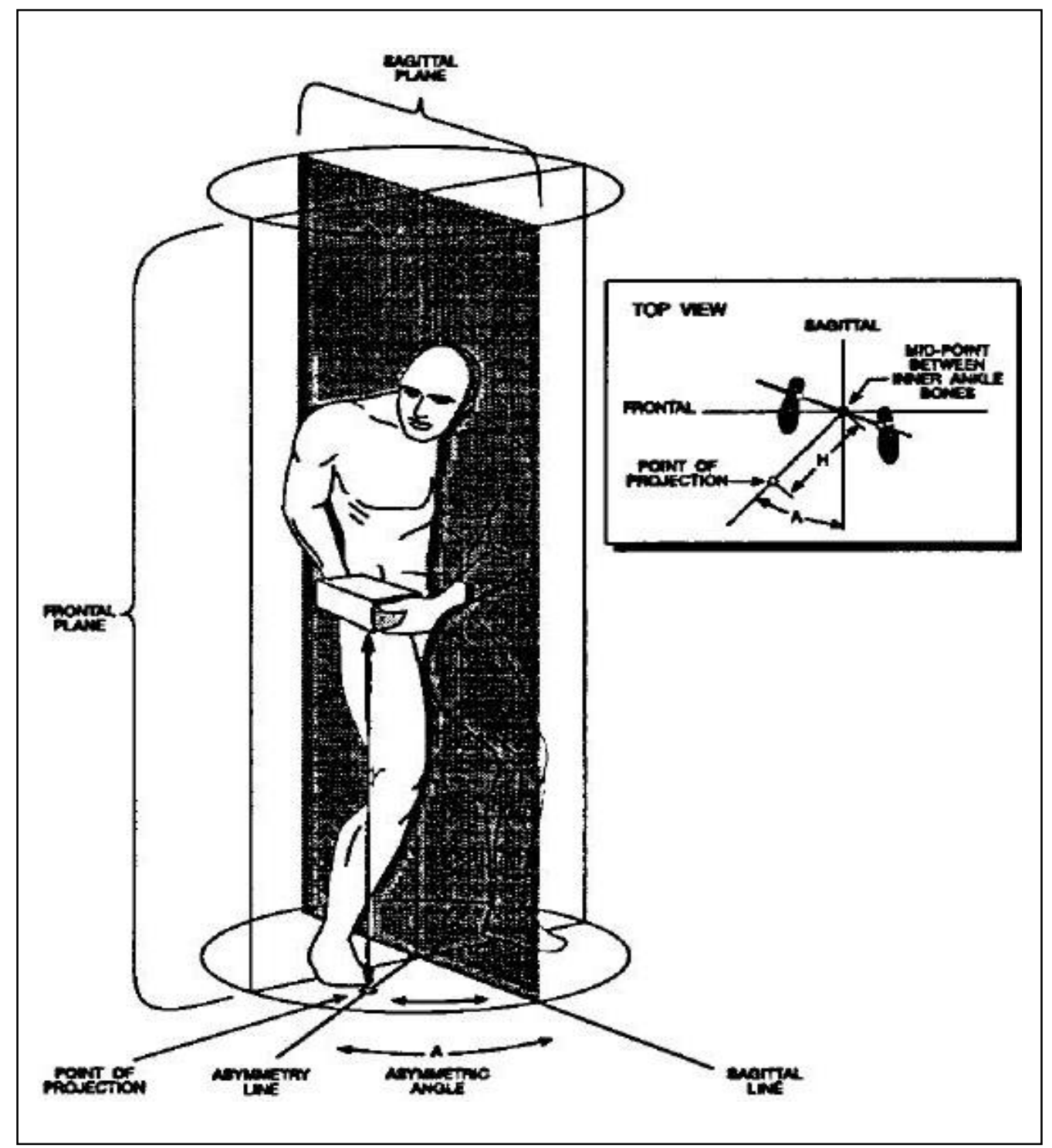

Figure 3.7 Graphic representation of angle of asymmetry (A) 


$$
L I=\frac{\text { Load Weight }}{\text { Recommended Weight Limit }}=\frac{L}{R W L}
$$

The Lifting Index (LI) is a term that provides a relative estimate of the level of physical stress associated with a particular manual lifting task. The estimate of the level of physical stress is defined by the relationship of the weight of the load lifted and the recommended weight limit. The smaller the LI is, the greater the fraction of workers capable of safely sustaining the level of activity. From the NIOSH perspective, it is likely that lifting tasks with a LI>1.0 pose an increased risk for lifting-related low back pain for some fraction of the workforce. Hence, the goal should be design all lifting jobs to achieve a LI of 1.0 or less. But some experts believe that worker selection criteria may be used to identify workers who can perform potentially stressful lifting task (i.e., lifting tasks that would exceed a LI of 1.0) without significantly increasing their risk of workrelated injury (Chaffin and Anderson, 1984; Ayoub and Mital, 1989). Nonetheless, these experts agree that nearly all workers will be at an increased risk of a work-related injury when performing highly stressful lifting task (i.e., lifting tasks that would exceed a LI of 3.0). In this research, due to the extreme weight of the blocks, we define that the lifting tasks with a LI $>3.0$ pose a significantly increased risk for lifting-related low back pain.

\subsubsection{Questionnaire:}

Subjects rated the level of difficulty among using different lifting methods and different height from 1 (Easily finish the task) to 10 (Barely finish the task). Based on these data, a 
diagram was provided to determine how different lifting methods and different height affect the workers feelings.

\subsection{Power Analysis}

Based on Model 1 and Model 2, the operating characteristic (OC) curves which is a plot of the type II error probability for a particular sample size versus a parameter can be used to assist the experiment in running a power analysis.

\subsubsection{Determination of the Number of Subjects:}

The random factor subject $\left(\gamma_{k}\right)$ is treated as a block, so here calculating the number of subjects is actually calculating the number of blocks. Based on the statistical Model 1 (or Model 2), the OC curves (for random model) is used with

$$
\lambda=\sqrt{1+\frac{c \sigma_{\gamma}{ }^{2}}{\sigma^{2}}}
$$

where

$$
\sigma_{\gamma}^{2}=M S B L, \sigma^{2}=M S E
$$

History data was collected from four subjects and three replications. MSBL and MSE are calculated. For four subjects ( $c=4$ ), by OC curve, it is found that $\beta \approx 0.44$. Therefore, the power of the test is approximately $1-\beta=1-0.44=0.56$, which is less than the preselected power request: 0.90 . Proceeding in a similar manner, table 3.2 shows the power for different number of subjects for Model 1 (beginning position of lifting). 
Table 3.2 Power value for different subjects

\begin{tabular}{|c|c|c|c|}
\hline $\mathrm{c}$ & $\lambda$ & $\beta$ & Power(1- $\beta)$ \\
\hline 4 & 2.5 & 0.44 & 0.56 \\
\hline 5 & 3.0 & 0.1 & 0.9 \\
\hline 6 & 3.3 & 0.035 & 0.965 \\
\hline
\end{tabular}

Thus, based on the Model 1, 5 subjects (blocks) are sufficient to obtain a test with the required power. The same method is used to determine the number of subjects for Model 2 , the number of subjects equals to 6 . Six subjects will be chosen for this study to insure both power requests for two models.

\subsubsection{Determination of the Number of Replicates:}

The method of determining the number of replicates is very similar as determining the number of subjects. The OC curves (for fix model) are used with:

Table 3.3 OC curve parameters for fix model.

\begin{tabular}{|c|c|c|c|}
\hline Factor & Parameter & $\mathrm{V} 1$ & $\mathrm{~V} 2$ \\
\hline $\mathrm{T}$ & $\Phi^{2}=\frac{b n \sum \tau_{i}{ }^{2}}{a \sigma^{2}}$ & $\mathrm{a}-1$ & $\mathrm{ab}(\mathrm{n}-1)$ \\
\hline $\mathrm{B}$ & $\Phi^{2}=\frac{a n \sum \beta_{j}{ }^{2}}{b \sigma^{2}}$ & $\mathrm{~b}-1$ & $\mathrm{ab}(\mathrm{n}-1)$ \\
\hline$\tau \beta$ & $\Phi^{2}=\frac{n \sum \sum \tau \beta_{i j}{ }^{2}}{\sigma^{2}[(a-1)(b-1)+1]}$ & $(\mathrm{a}-1)(\mathrm{b}-1)$ & $\mathrm{ab}(\mathrm{n}-1)$ \\
\hline
\end{tabular}


The ANOVA table based on history data shows that lifting height $\left(\tau_{\mathrm{i}}\right)$ is not significant in Model 1 (beginning position of lifting). 5 minimum numbers of replicates for 5 other fixed effects (two from Model 1 and three from Model 2) are calculated. Determination of replicates from factor lifting ways $(\beta \mathrm{j})$ in Model 2 is shown as an example in Table 3.3.

Table 3.4 Power value for different replicates

\begin{tabular}{|c|c|c|c|}
\hline $\mathrm{n}$ & $\Phi$ & $\beta$ & Power(1- $\beta$ ) \\
\hline 3 & 1.9 & 0.27 & 0.73 \\
\hline 4 & 2.2 & 0.16 & 0.84 \\
\hline 5 & 2.5 & 0.075 & 0.925 \\
\hline
\end{tabular}

Five replicates as the largest number of replicates will be applied to insure the sufficient power requests for two models. 


\section{Chapter 4: Results}

\subsection{Low Back Pressure Compression:}

Based on the values of low back pressure compressions, Figure 4.1 shows us the two ANOVA table for Model 1 and Model 2.

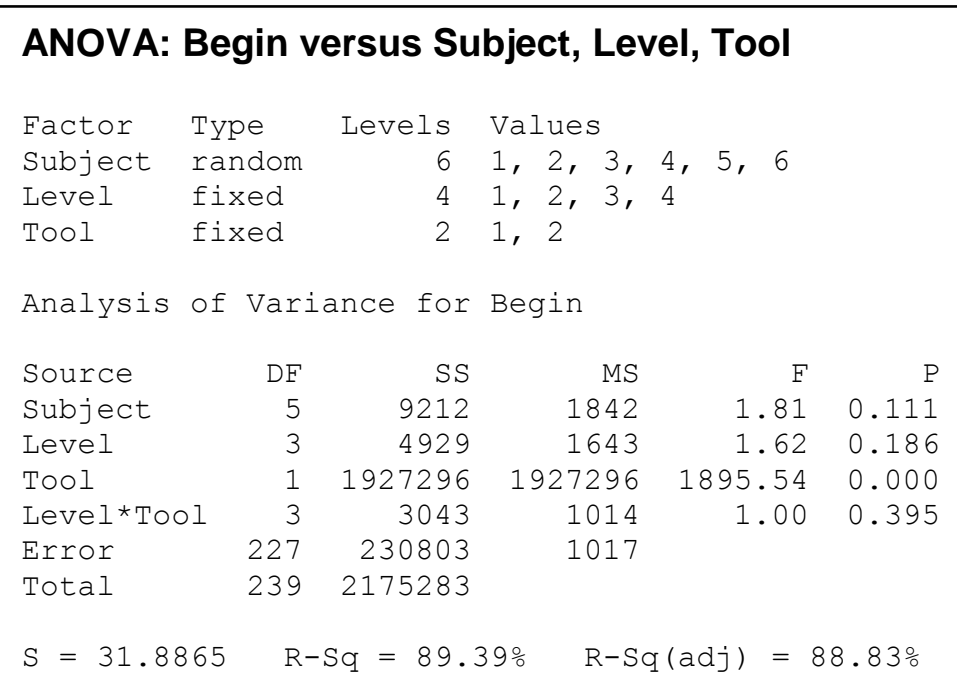

\section{ANOVA: End versus Subject, Level, Tool}

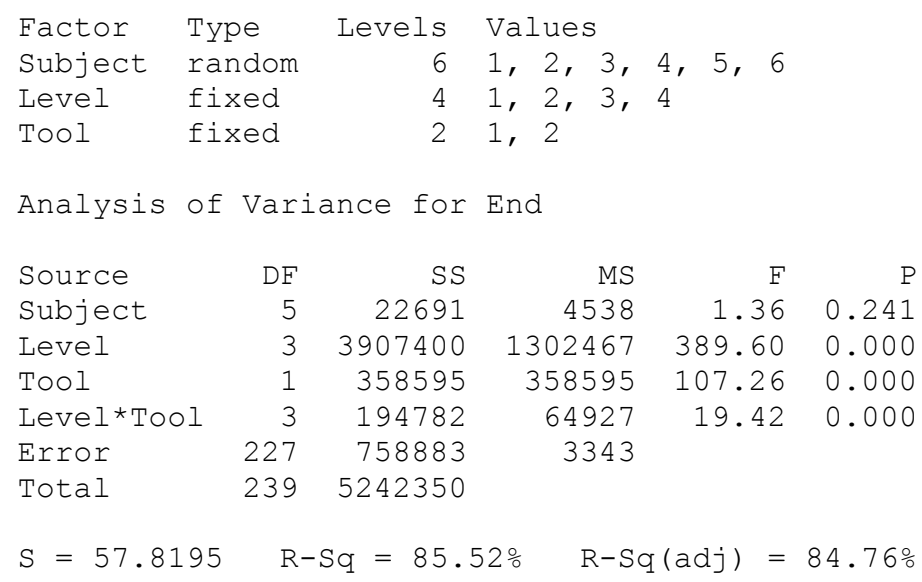

Figure 4.1 ANOVA tables for Model 1 and Model 2 
The ANOVA table for the beginning of the lift indicates that the tool has a significant effect on low back compression since its p-value is less than 0.05 and there is no sufficient statistical evidences to conclude other factors have effects on people's low back compression since their p-values are greater than significant level 0.05 .

The ANOVA table for the destination of the lifting task indicates that there is no sufficient statistical evidence to conclude that differences between subjects have an effect on low back compression since its p-value is greater than significant level 0.05 and statistically speaking other factors have effects on people's low back pressure since their p-values are less than 0.05 .

Furthermore, for Model 1, the tool effects have been calculated as follows: $\beta_{j}=\overline{y_{{ }_{j} .} .}-\overline{y_{\ldots .}}$

Then $\beta_{1}=-90$ and $\beta_{2}=90$. Here $\mathrm{j}=1$ represents with tool and $\mathrm{j}=2$ represents without tool. Since only Tool affects low back compression at the beginning position, it is concluded that the lifting tool helps to reduce people's low back compression at the beginning position for masonry task.

For Model 2, since level has effect on low back compression, comprehensive tool effects are calculated as follows: 


$$
\begin{aligned}
\beta_{j}+(\tau \beta)_{i j} & =\overline{y_{\cdot j} .}-\overline{y_{\ldots}}+\overline{y_{i j} .}-\overline{y_{i} \ldots}-\overline{y_{\cdot j} .}+\overline{y_{\ldots} \ldots} \\
& =\overline{y_{i j} .}-\overline{y_{i} \ldots}
\end{aligned}
$$

Then:

Table 4.1 Tool factor effects for different levels for Model 2

\begin{tabular}{|c|c|c|}
\hline \multirow{2}{*}{} & \multicolumn{2}{|c|}{$\mathrm{j}$} \\
\cline { 2 - 3 } & 1 & 2 \\
\hline$\beta_{\mathrm{j}}+(\tau \beta)_{1 \mathrm{j}}$ & -67 & 67 \\
\hline$\beta_{\mathrm{j}}+(\tau \beta)_{2 \mathrm{j}}$ & -26 & 26 \\
\hline$\beta_{\mathrm{j}}+(\tau \beta)_{3 \mathrm{j}}$ & -9 & 9 \\
\hline$\beta_{\mathrm{j}}+(\tau \beta)_{4 \mathrm{j}}$ & -21 & 21 \\
\hline
\end{tabular}

Again, $\mathrm{j}=1$ represents with tool and $\mathrm{j}=2$ represents without tool. Table 4.1 shows that the lifting tool helps to reduce people's low back compression for four different lifting level positions for masonry work.

\subsection{Strength Percent Capable Comparison:}

The origin of the lifting tasks was the same before lifts to, each of the four heights, so we don't need consider them separately. The strength capabilities of seven major joints, namely the wrist, elbow, shoulder, torso, hip, knee, and ankle are all above $25 \%$, depicting an acceptable strength requirement. Table 4.2 shows $95 \%$ confidence interval of strength capabilities for seven major joints at the beginning position. Based on the statistical results, only the knee resulted in significant differences tool use and manual lifting, where the strength capability of knee remains lower when using the tool compared to manual lifting. 
Table $4.295 \%$ confidence interval of strength capabilities for seven major joints at the beginning of the lifts.

\begin{tabular}{|c|c|c|}
\hline & \multicolumn{2}{|c|}{ 95\% Confidence Interval of Strength Capabilities } \\
\hline Major Joints & Tool & Manual \\
\hline Wrist & $(84.96,89.29)$ & $(86.96,89.88)$ \\
\hline Elbow & $(97.31,98.07)$ & $(97.94,98.39)$ \\
\hline Shoulder & $(98.47,98.89)$ & $(98.64,98.83)$ \\
\hline Torso & $(82.89,85.26)$ & $(84.37,85.91)$ \\
\hline Hip & $(73.93,77.06)$ & $(73.29,76.61)$ \\
\hline Knee & $(94.49,96.21)$ & $(81.44,85.90)$ \\
\hline Ankle & $(69.80,75.51)$ & $(75.03,79.20)$ \\
\hline
\end{tabular}

For the destination of the lifting tasks, the positions for all four heights are different, so they are considered separately. Table 4.3 shows $95 \%$ confidence interval of strength capabilities for seven major joints at the destination. Based on the statistical results, we can see at the lowest level, different lifting methods affect shoulder, and torso, and the strength capabilities of these two major joints when manual lifting are all higher than when using the tool. For level 2, using tool can reduce the strength capabilities of wrist, elbow and shoulder, but increase the strength capabilities of hip, knee, and ankle. At level 3, using tool affects wrist, elbow, and shoulder. The tool can help increase the strength capabilities of elbow, but decrease it of wrist and shoulder. At the highest level, there is no significant difference only in torso and hip, and the tool can also only help increase the strength capabilities of elbow. 
Table $4.395 \%$ confidence interval of strength capabilities for all major joints at the end.

\begin{tabular}{|c|c|c|}
\hline & \multicolumn{2}{|c|}{$95 \%$ Confidence Interval of the Strength Capability } \\
\hline & Tool & Manual \\
\hline Major Joints & \multicolumn{2}{|c|}{ Level 1} \\
\hline Wrist & $(66.56,78.50)$ & $(65.11,76.02)$ \\
\hline Elbow & $(94.04,96.96)$ & $(93.59,96.48)$ \\
\hline Shoulder & $(94.6696 .81)$ & $(97.00,98.00)$ \\
\hline Torso & $(38.80,48.33)$ & $(49.14,53.86)$ \\
\hline Hip & $(15.89,29.31)$ & $(11.25,20.95)$ \\
\hline Knee & $(7.97,15.69)$ & $(15.27,25.40)$ \\
\hline \multirow[t]{2}{*}{ Ankle } & $(4.20,8.80)$ & $(3.63,9.37)$ \\
\hline & \multicolumn{2}{|c|}{ Level 2} \\
\hline Wrist & $(34.21,40.32)$ & $(68.68,78.65)$ \\
\hline Elbow & $(84.50,87.50)$ & $(93.56,96.37)$ \\
\hline Shoulder & $(74.09,82.91)$ & $(90.77,93.70)$ \\
\hline Torso & $(51.29,59.11)$ & $(55.48,61.45)$ \\
\hline Hip & $(55.89,66.25)$ & $(32.80,46.66)$ \\
\hline Knee & $(31.69,43.17)$ & $(7.49,27.91)$ \\
\hline \multirow[t]{2}{*}{ Ankle } & $(23.79,33.54)$ & $(2.08,17.46)$ \\
\hline & \multicolumn{2}{|c|}{ Level 3} \\
\hline Wrist & $(0.62,1.38)$ & $27.86,33.61)$ \\
\hline Elbow & $(98.86,99.34)$ & $(81.70,88.03)$ \\
\hline Shoulder & $(15.76,22.58)$ & $(45.81,59.46)$ \\
\hline Torso & $(45.54,53.19)$ & $(48.13,59.41)$ \\
\hline Hip & $(44.90,54.30)$ & $(36.83,59.10)$ \\
\hline Knee & $(29.82,46.91)$ & $(15.23,44.04)$ \\
\hline \multirow[t]{2}{*}{ Ankle } & $(7.78,14.35)$ & $(10.42,23.78)$ \\
\hline & \multicolumn{2}{|c|}{ Level 4} \\
\hline Wrist & $(0,0.21)$ & $(12.38,18.02)$ \\
\hline Elbow & $(99.74,99.99)$ & $(89.45,92.68)$ \\
\hline Shoulder & $(9.43,14.04)$ & $(21.87,36.06)$ \\
\hline Torso & $(63.34,70.32)$ & $(54.38,65.48)$ \\
\hline Hip & $(52.57,60.76)$ & $(47.35,67.45)$ \\
\hline Knee & $(8.30,19.57)$ & $(27.39,50.48)$ \\
\hline Ankle & $(5.49,13.25)$ & $(22.95,39.11)$ \\
\hline
\end{tabular}


Table 4.4 shows all the major joints with strength capabilities that are below $25 \%$. It depicts all the major joint are shown in the table have an unacceptable strength requirement.

Table 4.4 Major joints of the strength capability which is below $25 \%$

\begin{tabular}{|c|c|c|}
\hline & Level & Major Joint \\
\hline \multirow{4}{*}{ Tool } & 1 & Knee, Ankle. \\
\cline { 2 - 3 } & 2 & None \\
\cline { 2 - 3 } & 3 & Wrist, Shoulder, Ankle \\
\cline { 2 - 3 } & 4 & Wrist, Shoulder, Knee, Ankle \\
\hline \multirow{4}{*}{ Manual } & 1 & Hip, Knee, Ankle. \\
\cline { 2 - 3 } & 2 & Knee, Ankle. \\
\cline { 2 - 3 } & 3 & Ankle \\
\cline { 2 - 3 } & 4 & Wrist \\
\hline
\end{tabular}

\subsection{NIOSH Lifting Equation:}

We used NIOSH Lifting Equation to estimate if the lifting tasks pose a significantly increased risk for lifting-related low back pain. Based on the equation, all LI values between two lifting method and four lifting heights were calculated, as shown in table 4.5. And all the values of the six variables, six coefficients, and RWL, see Table A.7-A.8 in Appendix II. 
Table 4.5 LI value between two lifting method and four lifting heights

\begin{tabular}{|c|c|c|c|c|}
\hline \multicolumn{5}{|c|}{ LI } \\
\hline \multirow{2}{*}{} & \multicolumn{2}{|c|}{ Manual } & \multicolumn{2}{c|}{ Tool } \\
\cline { 2 - 5 } & Begin & End & Begin & End \\
\hline $1.5 \mathrm{ft}$ & 2.95 & 5.02 & 2.52 & 4.38 \\
\hline $2.5 \mathrm{ft}$ & 3.09 & 4.25 & 2.63 & 4.07 \\
\hline $3.5 \mathrm{ft}$ & 3.12 & 4.72 & 2.66 & 4.58 \\
\hline $4.5 \mathrm{ft}$ & 3.20 & 5.36 & 2.72 & 5.27 \\
\hline
\end{tabular}

From the table above, we can see at the beginning position, the LI values are higher than 3 except at the lowest level when hand lifting, and less than 3 when using tool. At the ending position, all LI values are bigger than 3. And the LI values at all four height levels remain lower of using tool comparing to manual lifting task at both the origin and destination. The lower value is getting less as the height raises at the destination of the lifting tasks, which becomes very closed at the highest level.

\subsection{Questionnaire:}

The difficulty among using different lifting methods and different height for each subject are displayed in figure 4.2 . 


\section{Subject 1}

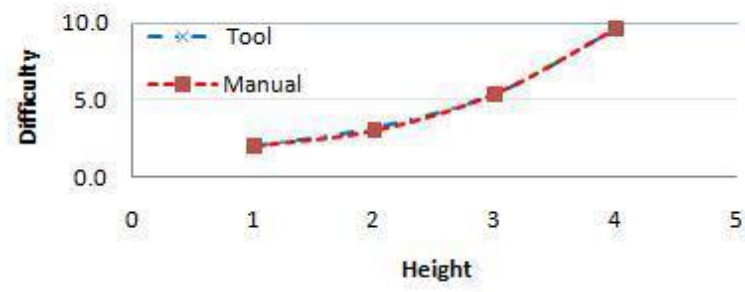

Suject 3

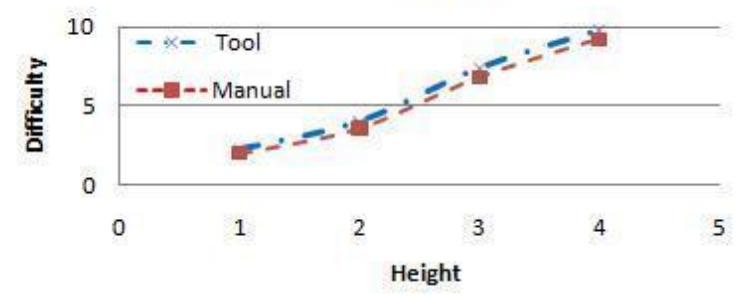

Subject 5

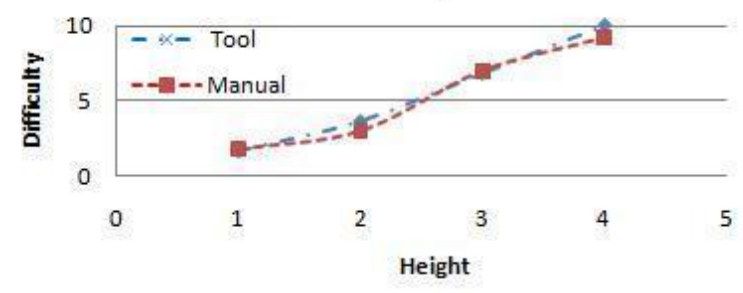

Subject 2

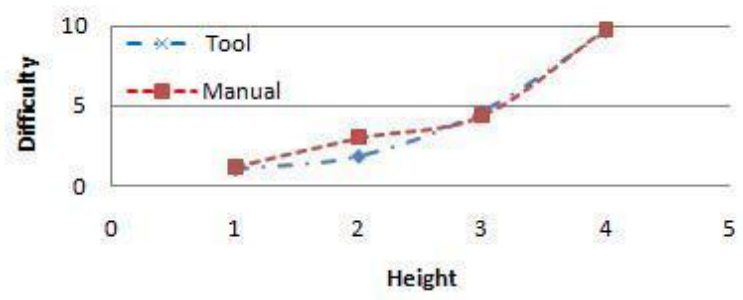

Subject 4

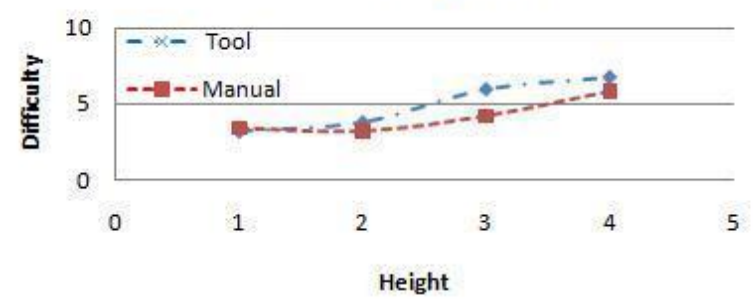

Subject 6

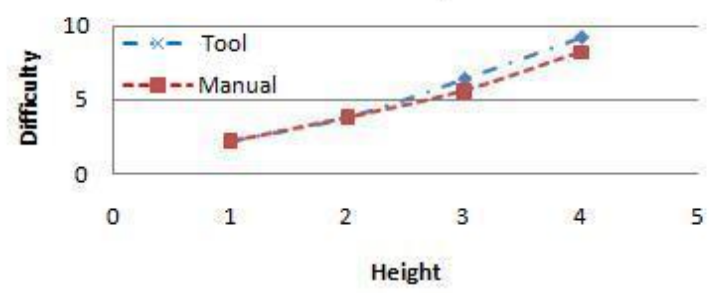

Figure 4.2 Perceived difficulty among subjects using different lifting methods at different heights

From Figure 4.2, the difficulty for the different height level indicated, as the height level increases from 1 to 4, the difficulty level rises in the phases. And we can also see that subjects felt without tool is easier more often than using tool, especially at the high level of the height. 


\section{Chapter 5: Discussion and Conclusion}

This study revealed that using Versa-Lok Lifter has significant effect for workers.

The apparent difference in the value between tool and manual lifting was observed for the low back compression and LI, where the value of low back compression and LI are always lower for tool lifting. These results suggest that the risk of a low back injury can be reduced by use of Versa-Lifter. We also found that the values of low back compression and LI decrease as height increases when the lifting level is below $2.5 \mathrm{ft}$, but increase as the height increases above 2.5ft. A final observation is that all LIs at the destination are above 3. Recall that we defined that lifting tasks with a LI greater than 3.0 pose a significantly increased risk for lifting-related low back pain. Therefore, using Versa-Lifter can reduce the risk of a low back injury, but a significant percentage of the workforce is still likely to be at risk for developing lifting-related low back pain whether or not they are using the lifting tool.

The masons who participated in this study performed the experiment in the laboratory, which may not have been identical to actual fieldwork. Prior to the experiment, two masons were consulted on the setup to increase the fidelity of the environment. The subjects stated that the tasks were "very similar" to what they experience on the job, and concurred that the setup can be considered representative of one aspect of typical 
residential retaining wall construction. An additional limitation is that some masons stepped toward the wall with only the left foot bringing it 90 degrees to the left, while others turned both feet toward the wall during the lifts. The data shows that the strength capabilities of subjects' knee and ankle are close to zero when they pivoting the right foot, especially at high levels, and above $25 \%$ when they bringing both feet 90 degrees. And we also found that the subjects turn only one foot more often at the low levels. Hence, the significant effects of subjects' knees and ankles might not be caused by different lifting ways, but different positions. And based on these data, we recommend masons to turn both feet when they remaining the wall as possible as they can.

The data of the strength capabilities also indicate that, at the beginning position, the strength requirements are acceptable for all seven major joints, and tool lifting may increase the risk of knee injury, because the masons have to lower their body further to the ground to lift the same block, thus having to lift the body and block 12 inch further up to place the block. Meanwhile for the ending position, using tool has effects on most of the joints, using tool is better for the elbow, but may have risks for wrist and shoulder, especially at the high level, since there is an adverse effect of working with the arms elevated at or above shoulder level, and masons have to elevate both the arm 12 inches more by using tool. As the data shows, when the lifting height is above $2.5 \mathrm{ft}$, the strength capabilities of wrist and shoulder are always much higher than manual lifting, the values of wrist are close to zero when using tool, which means using tool is hazardous for wrist and shoulder at high levels. 
It was somewhat surprising that the participants indicated manual lifting is easier more often than when using the tool, especially at the higher levels. It is possible that the masons expected a higher force when the height gets higher, and another reason is that they may be unaccustomed get use to the tool.

Consequently, from the present study it was concluded that using Versa-Lifter can reduce the low back compression, but the percentage of the low back pain incidence rate is still high, especially, at the higher levels. And based on the values of LIs, the positive effect of using tool is getting less as the lifting height increases. Additionally using tool still may increase risks for some major joints of human body at higher level. Therefore, using Versa-Lifter is better for the lower levels but still need optimizations for the higher levels. 


\section{APPENDIX I}

Table A1.1 Average angle and low back compression for subject 1 with tool lifting

\begin{tabular}{|c|c|c|c|c|c|c|c|c|c|c|c|}
\hline & \multirow{3}{*}{ Subject 1} & \multicolumn{10}{|c|}{ Average Angle } \\
\hline & & \multicolumn{2}{|c|}{ Begin } & \multicolumn{2}{|c|}{ end(level 1) } & \multicolumn{2}{|c|}{ end(level 2) } & \multicolumn{2}{|c|}{ end(level 3) } & \multicolumn{2}{|c|}{ end(level 4) } \\
\hline & & horizontal & vertical & horizontal & vertical & horizontal & vertical & horizontal & vertical & horizontal & vertical \\
\hline \multirow{5}{*}{ left } & left forearm & 142 & -54 & 106 & -58 & 129 & -29 & 131 & -17 & 154 & -18 \\
\hline & left upper arm & 63 & -79 & 62 & -73 & 39 & -60 & 69 & -17 & 53 & -1 \\
\hline & left upper leg & 66 & 16 & 87 & -74 & 90 & -91 & 81 & -76 & -11 & -89 \\
\hline & left lower leg & -118 & -25 & -89 & -80 & -88 & -85 & -90 & -71 & -13 & -89 \\
\hline & left foot & 57 & -1 & 140 & -3 & 92 & 1 & 87 & -1 & 111 & 2 \\
\hline \multirow{5}{*}{ right } & right forearm & 133 & -50 & 114 & -65 & 131 & -26 & 120 & -11 & 150 & 4 \\
\hline & right upper arm & 44 & -88 & 60 & -78 & 48 & -57 & 70 & -14 & 32 & -3 \\
\hline & right upper leg & 25 & 17 & -28 & -76 & -88 & -88 & 63 & 61 & -124 & -87 \\
\hline & right lower leg & -114 & -25 & -147 & -59 & -85 & -85 & -99 & -76 & -96 & -57 \\
\hline & right foot & 55 & -5 & 6 & -24 & 74 & 1 & 73 & 2 & 46 & -39 \\
\hline trunk & flexion & \multicolumn{2}{|c|}{49} & \multicolumn{2}{|c|}{44} & \multicolumn{2}{|c|}{67} & \multicolumn{2}{|c|}{79} & \multicolumn{2}{|c|}{92} \\
\hline \multicolumn{2}{|c|}{$\begin{array}{c}\text { Average Low Back } \\
\text { Compression }\end{array}$} & \multicolumn{2}{|c|}{1091} & \multicolumn{2}{|c|}{1028} & \multicolumn{2}{|c|}{738} & \multicolumn{2}{|c|}{752} & \multicolumn{2}{|c|}{695} \\
\hline
\end{tabular}


Table A1.2 Average angle and low back compression for subject 1 with manual lifting

\begin{tabular}{|c|c|c|c|c|c|c|c|c|c|c|c|}
\hline & \multirow{3}{*}{ Subject $1 `$} & \multicolumn{10}{|c|}{ Average Angle } \\
\hline & & \multicolumn{2}{|c|}{ begin } & \multicolumn{2}{|c|}{ end(level 1) } & \multicolumn{2}{|c|}{ end(level 2) } & \multicolumn{2}{|c|}{ end(level 3) } & \multicolumn{2}{|c|}{ end(level 4) } \\
\hline & & horizontal & vertical & horizontal & vertical & horizontal & vertical & horizontal & vertical & horizontal & vertical \\
\hline \multirow{5}{*}{ left } & left forearm & 102 & -60 & 93 & -43 & 108 & -53 & 117 & 1 & 114 & 12 \\
\hline & left upper arm & -35 & -78 & -1 & -71 & 19 & -66 & 26 & -51 & 9 & -47 \\
\hline & left upper leg & 65 & -11 & 88 & -54 & 89 & -83 & 62 & -84 & -37 & -85 \\
\hline & left lower leg & -115 & -21 & -99 & -74 & -87 & -83 & -91 & -74 & -43 & -87 \\
\hline & left foot & 51 & -24 & 132 & -2 & 92 & -13 & 107 & -5 & 91 & -22 \\
\hline \multirow{5}{*}{ right } & right forearm & 113 & -67 & 86 & -62 & 108 & -59 & 120 & 0 & 110 & 4 \\
\hline & right upper arm & -28 & -79 & 2 & -59 & -1 & -69 & 22 & -43 & 11 & -45 \\
\hline & right upper leg & 64 & -9 & 52 & -69 & -21 & -84 & -18 & -83 & -113 & -86 \\
\hline & right lower leg & -114 & -26 & -148 & -55 & -115 & -38 & -78 & -80 & -95 & -90 \\
\hline & right foot & 56 & -8 & 9 & -17 & 60 & -20 & 74 & 1 & 99 & -15 \\
\hline trunk & flexion & \multicolumn{2}{|c|}{28} & \multicolumn{2}{|c|}{26} & \multicolumn{2}{|c|}{65} & \multicolumn{2}{|c|}{82} & \multicolumn{2}{|c|}{81} \\
\hline \multicolumn{2}{|c|}{$\begin{array}{c}\text { Average Low Back } \\
\text { Compression }\end{array}$} & \multicolumn{2}{|c|}{1267} & \multicolumn{2}{|c|}{1182} & \multicolumn{2}{|c|}{762} & \multicolumn{2}{|c|}{780} & \multicolumn{2}{|c|}{707} \\
\hline
\end{tabular}


Table A1.3 Average angle and low back compression for subject 2 with tool lifting

\begin{tabular}{|c|c|c|c|c|c|c|c|c|c|c|c|}
\hline & \multirow{3}{*}{ Subject 2} & \multicolumn{10}{|c|}{ Average Angle } \\
\hline & & \multicolumn{2}{|c|}{ begin } & \multicolumn{2}{|c|}{ end(level 1) } & \multicolumn{2}{|c|}{ end(level 2) } & \multicolumn{2}{|c|}{ end(level 3) } & \multicolumn{2}{|c|}{ end(level 4) } \\
\hline & & horizontal & vertical & horizontal & vertical & horizontal & vertical & horizontal & vertical & horizontal & vertical \\
\hline \multirow{5}{*}{ left } & left forearm & 140 & -59 & 116 & -59 & 127 & -32 & 132 & -17 & 149 & -27 \\
\hline & left upper arm & 61 & -80 & 88 & -76 & 41 & -61 & 65 & -16 & 54 & 13 \\
\hline & left upper leg & 51 & -8 & 83 & -69 & 85 & -87 & 80 & -83 & -25 & -87 \\
\hline & left lower leg & -113 & -19 & -92 & -83 & -94 & -86 & -88 & -74 & -3 & -88 \\
\hline & left foot & 58 & 0 & 140 & -2 & 92 & -2 & 90 & -3 & 109 & 0 \\
\hline \multirow{5}{*}{ right } & right forearm & 138 & -47 & 101 & -66 & 130 & -27 & 127 & -9 & 160 & -6 \\
\hline & right upper arm & 38 & -85 & 92 & -69 & 47 & -58 & 61 & -17 & 33 & -7 \\
\hline & right upper leg & 36 & 2 & -17 & -78 & -89 & -89 & 59 & -32 & -120 & -84 \\
\hline & right lower leg & -101 & -21 & -153 & -58 & -84 & -84 & -97 & -78 & -90 & -72 \\
\hline & right foot & 48 & -2 & -6 & -20 & 77 & -9 & 70 & -1 & 50 & -36 \\
\hline trunk & flexion & \multicolumn{2}{|c|}{55} & \multicolumn{2}{|c|}{48} & \multicolumn{2}{|c|}{71} & \multicolumn{2}{|c|}{81} & \multicolumn{2}{|c|}{84} \\
\hline \multicolumn{2}{|c|}{$\begin{array}{c}\text { Average Low Back } \\
\text { Compression }\end{array}$} & \multicolumn{2}{|c|}{1083} & \multicolumn{2}{|c|}{866} & \multicolumn{2}{|c|}{745} & \multicolumn{2}{|c|}{783} & \multicolumn{2}{|c|}{660} \\
\hline
\end{tabular}


Table A1.4 Average angle and low back compression for subject 2 with manual lifting

\begin{tabular}{|c|c|c|c|c|c|c|c|c|c|c|c|}
\hline & \multirow{3}{*}{ Subject 2} & \multicolumn{10}{|c|}{ Average Angle } \\
\hline & & \multicolumn{2}{|c|}{ begin } & \multicolumn{2}{|c|}{ end(level 1) } & \multicolumn{2}{|c|}{ end(level 2) } & \multicolumn{2}{|c|}{ end(level 3) } & \multicolumn{2}{|c|}{ end(level 4) } \\
\hline & & horizontal & vertical & horizontal & vertical & horizontal & vertical & horizontal & vertical & horizontal & vertical \\
\hline \multirow{5}{*}{ left } & left forearm & 117 & -71 & 105 & -59 & 109 & -52 & 115 & 0 & 118 & 13 \\
\hline & left upper arm & -40 & -68 & -4 & -68 & 23 & -68 & 28 & -50 & 10 & -50 \\
\hline & left upper leg & 62 & -10 & 84 & -53 & 88 & -84 & 61 & -80 & 2 & -84 \\
\hline & left lower leg & -118 & -21 & -101 & -72 & -90 & -90 & -92 & -78 & -2 & -85 \\
\hline & left foot & 54 & -19 & 133 & -5 & 88 & -14 & 106 & -12 & 83 & -21 \\
\hline \multirow{5}{*}{ right } & right forearm & 95 & -63 & 92 & -53 & 100 & -60 & 124 & 4 & 110 & 7 \\
\hline & right upper arm & 1 & -68 & -12 & -57 & -3 & -72 & 28 & -44 & 11 & -48 \\
\hline & right upper leg & 70 & -17 & 46 & -74 & -20 & -78 & -7 & -81 & -98 & -88 \\
\hline & right lower leg & -114 & -25 & -149 & -57 & -93 & -13 & -90 & -77 & -93 & -89 \\
\hline & right foot & 52 & -7 & -9 & -16 & 36 & -24 & 81 & -6 & 75 & -11 \\
\hline trunk & flexion & \multicolumn{2}{|c|}{35} & \multicolumn{2}{|c|}{24} & \multicolumn{2}{|c|}{58} & \multicolumn{2}{|c|}{85} & \multicolumn{2}{|c|}{83} \\
\hline \multicolumn{2}{|c|}{$\begin{array}{c}\text { Average Low Back } \\
\text { Compression }\end{array}$} & \multicolumn{2}{|c|}{1239} & \multicolumn{2}{|c|}{1024} & \multicolumn{2}{|c|}{810} & \multicolumn{2}{|c|}{812} & \multicolumn{2}{|c|}{811} \\
\hline
\end{tabular}


Table A1.5 Average angle and low back compression for subject 3 with tool lifting

\begin{tabular}{|c|c|c|c|c|c|c|c|c|c|c|c|}
\hline & \multirow{3}{*}{ Subject 3} & \multicolumn{10}{|c|}{ Average Angle } \\
\hline & & \multicolumn{2}{|c|}{ begin } & \multicolumn{2}{|c|}{ end(level 1) } & \multicolumn{2}{|c|}{ end(level 2) } & \multicolumn{2}{|c|}{ end(level 3) } & \multicolumn{2}{|c|}{ end(level 4) } \\
\hline & & horizontal & vertical & horizontal & vertical & horizontal & vertical & horizontal & vertical & horizontal & vertical \\
\hline \multirow{5}{*}{ left } & left forearm & 141 & -66 & 111 & -60 & 127 & -30 & 129 & -17 & 151 & -22 \\
\hline & left upper arm & 72 & -76 & 93 & -75 & 43 & -61 & 67 & -16 & 51 & 14 \\
\hline & left upper leg & 37 & -11 & 86 & -77 & 76 & -92 & 70 & -71 & -37 & -87 \\
\hline & left lower leg & -114 & -27 & -84 & -78 & -95 & -90 & -88 & -71 & -13 & -88 \\
\hline & left foot & 52 & 2 & 133 & -3 & 94 & -1 & 88 & -2 & 109 & 0 \\
\hline \multirow{5}{*}{ right } & right forearm & 132 & -66 & 118 & -70 & 128 & -29 & 120 & -17 & 161 & -6 \\
\hline & right upper arm & 56 & -81 & 81 & -70 & 45 & -62 & 64 & -22 & 32 & 2 \\
\hline & right upper leg & 52 & -2 & -19 & -71 & -99 & -88 & 51 & -44 & -130 & -88 \\
\hline & right lower leg & -101 & -20 & -147 & -55 & -89 & -87 & -99 & -70 & -91 & -71 \\
\hline & right foot & 50 & -2 & -3 & -22 & 75 & 4 & 67 & -9 & 46 & -30 \\
\hline trunk & flexion & \multicolumn{2}{|c|}{61} & \multicolumn{2}{|c|}{36} & \multicolumn{2}{|c|}{70} & \multicolumn{2}{|c|}{85} & \multicolumn{2}{|c|}{84} \\
\hline \multicolumn{2}{|c|}{$\begin{array}{c}\text { Average Low Back } \\
\text { Compression }\end{array}$} & \multicolumn{2}{|c|}{1082} & \multicolumn{2}{|c|}{940} & \multicolumn{2}{|c|}{770} & \multicolumn{2}{|c|}{802} & \multicolumn{2}{|c|}{727} \\
\hline
\end{tabular}


Table A1.6 Average angle and low back compression for subject 3 with manual lifting

\begin{tabular}{|c|c|c|c|c|c|c|c|c|c|c|c|}
\hline & \multirow{3}{*}{ Subject 3} & \multicolumn{10}{|c|}{ Average Angle } \\
\hline & & \multicolumn{2}{|c|}{ begin } & \multicolumn{2}{|c|}{ end(level 1) } & \multicolumn{2}{|c|}{ end(level 2) } & \multicolumn{2}{|c|}{ end(level 3) } & \multicolumn{2}{|c|}{ end(level 4) } \\
\hline & & horizontal & vertical & horizontal & vertical & horizontal & vertical & horizontal & vertical & horizontal & vertical \\
\hline \multirow{5}{*}{ left } & left forearm & 112 & -70 & 102 & -49 & 99 & -54 & 115 & 1 & 117 & 9 \\
\hline & left upper arm & -14 & -78 & 35 & -70 & 64 & -70 & 26 & -49 & 9 & -48 \\
\hline & left upper leg & 63 & -11 & 82 & -53 & 90 & -83 & 65 & -80 & -28 & -89 \\
\hline & left lower leg & -114 & -28 & -101 & -70 & -88 & -92 & -89 & -76 & -13 & -87 \\
\hline & left foot & 52 & -22 & 126 & -4 & 130 & -16 & 79 & -12 & 84 & -23 \\
\hline \multirow{5}{*}{ right } & right forearm & 97 & -69 & 88 & -59 & 102 & -55 & 130 & 5 & 106 & 7 \\
\hline & right upper arm & -31 & -75 & -11 & -65 & 23 & -71 & 31 & -56 & 10 & -48 \\
\hline & right upper leg & 66 & -15 & 39 & -72 & -34 & -76 & -17 & -83 & -118 & -88 \\
\hline & right lower leg & -111 & -26 & -148 & -55 & -92 & -20 & -83 & -75 & -120 & -87 \\
\hline & right foot & 54 & -6 & -3 & -23 & 29 & -15 & 58 & 2 & 74 & -16 \\
\hline trunk & flexion & \multicolumn{2}{|c|}{28} & \multicolumn{2}{|c|}{19} & \multicolumn{2}{|c|}{55} & \multicolumn{2}{|c|}{81} & \multicolumn{2}{|c|}{82} \\
\hline \multicolumn{2}{|c|}{$\begin{array}{c}\text { Average Low Back } \\
\text { Compression }\end{array}$} & \multicolumn{2}{|c|}{1267} & \multicolumn{2}{|c|}{1015} & \multicolumn{2}{|c|}{830} & \multicolumn{2}{|c|}{824} & \multicolumn{2}{|c|}{831} \\
\hline
\end{tabular}


Table A1.7 Average angle and low back compression for subject 4 with tool lifting

\begin{tabular}{|c|c|c|c|c|c|c|c|c|c|c|c|}
\hline & \multirow{3}{*}{ Subject 4} & \multicolumn{10}{|c|}{ Average Angle } \\
\hline & & \multicolumn{2}{|c|}{ begin } & \multicolumn{2}{|c|}{ end(level 1) } & \multicolumn{2}{|c|}{ end(level 2) } & \multicolumn{2}{|c|}{ end(level 3) } & \multicolumn{2}{|c|}{ end(level 4) } \\
\hline & & horizontal & vertical & horizontal & vertical & horizontal & vertical & horizontal & vertical & horizontal & vertical \\
\hline \multirow{5}{*}{ left } & left forearm & 122 & -63 & 106 & -60 & 129 & -29 & 132 & -16 & 152 & -23 \\
\hline & left upper arm & 70 & -78 & 61 & -78 & 39 & -61 & 65 & -18 & 54 & 15 \\
\hline & left upper leg & 42 & 19 & 75 & -77 & 89 & -85 & 52 & -75 & -11 & -89 \\
\hline & left lower leg & -100 & -27 & -91 & -87 & -92 & -92 & -92 & -72 & -19 & -89 \\
\hline & left foot & 53 & -3 & 140 & -4 & 95 & -4 & 94 & -3 & 112 & 0 \\
\hline \multirow{5}{*}{ right } & right forearm & 136 & -52 & 110 & -64 & 129 & -27 & 131 & -16 & 158 & -8 \\
\hline & right upper arm & 68 & -76 & 53 & -70 & 46 & -56 & 66 & -22 & 32 & -3 \\
\hline & right upper leg & 54 & 16 & -23 & -74 & -96 & -88 & 52 & 51 & -124 & -86 \\
\hline & right lower leg & -103 & -27 & -151 & -64 & -88 & -87 & -100 & -72 & -90 & -57 \\
\hline & right foot & 49 & -4 & -20 & -18 & 74 & -7 & 73 & 3 & 56 & 1 \\
\hline trunk & flexion & \multicolumn{2}{|c|}{61} & \multicolumn{2}{|c|}{37} & \multicolumn{2}{|c|}{78} & \multicolumn{2}{|c|}{80} & \multicolumn{2}{|c|}{84} \\
\hline & $\begin{array}{l}\text { rage Low Back } \\
\text { ompression }\end{array}$ & \multicolumn{2}{|c|}{1080} & \multicolumn{2}{|c|}{999} & \multicolumn{2}{|c|}{728} & \multicolumn{2}{|c|}{805} & \multicolumn{2}{|c|}{643} \\
\hline
\end{tabular}


Table A1.8 Average angle and low back compression for subject 4 with manual lifting

\begin{tabular}{|c|c|c|c|c|c|c|c|c|c|c|c|}
\hline & \multirow{3}{*}{ Subject 4} & \multicolumn{10}{|c|}{ Average Angle } \\
\hline & & \multicolumn{2}{|c|}{ begin } & \multicolumn{2}{|c|}{ end(level 1) } & \multicolumn{2}{|c|}{ end(level 2) } & \multicolumn{2}{|c|}{ end(level 3) } & \multicolumn{2}{|c|}{ end(level 4) } \\
\hline & & horizontal & vertical & horizontal & vertical & horizontal & vertical & horizontal & vertical & horizontal & vertical \\
\hline \multirow{5}{*}{ left } & left forearm & 120 & -71 & 96 & -61 & 109 & -54 & 113 & 1 & 115 & 14 \\
\hline & left upper arm & -22 & -73 & -7 & -67 & 53 & -66 & 37 & -50 & 11 & -46 \\
\hline & left upper leg & 64 & -12 & 96 & -53 & 79 & -92 & 65 & -83 & -45 & -84 \\
\hline & left lower leg & -113 & -19 & -100 & -70 & -92 & -87 & -89 & -75 & -11 & -86 \\
\hline & left foot & 53 & -25 & 124 & -3 & 96 & -16 & 90 & -4 & 82 & -21 \\
\hline \multirow{5}{*}{ right } & right forearm & 115 & -65 & 83 & -55 & 105 & -53 & 120 & 1 & 106 & 8 \\
\hline & right upper arm & -23 & -78 & 0 & -60 & 16 & -68 & 25 & -45 & 13 & -48 \\
\hline & right upper leg & 64 & -15 & 54 & -69 & -36 & -76 & 27 & -81 & -112 & -89 \\
\hline & right lower leg & -115 & -24 & -149 & -58 & -111 & -23 & -86 & -77 & -106 & -88 \\
\hline & right foot & 55 & -1 & 6 & -16 & 61 & -20 & 68 & -1 & 88 & -16 \\
\hline trunk & flexion & \multicolumn{2}{|c|}{38} & \multicolumn{2}{|c|}{21} & \multicolumn{2}{|c|}{59} & \multicolumn{2}{|c|}{81} & \multicolumn{2}{|c|}{84} \\
\hline & $\begin{array}{l}\text { rage Low Back } \\
\text { ompression }\end{array}$ & \multicolumn{2}{|c|}{1266} & \multicolumn{2}{|c|}{1277} & \multicolumn{2}{|c|}{790} & \multicolumn{2}{|c|}{816} & \multicolumn{2}{|c|}{671} \\
\hline
\end{tabular}


Table A1.9 Average angle and low back compression for subject 5 with tool lifting

\begin{tabular}{|c|c|c|c|c|c|c|c|c|c|c|c|}
\hline & \multirow{3}{*}{ Subject 5} & \multicolumn{10}{|c|}{ Average Angle } \\
\hline & & \multicolumn{2}{|c|}{ begin } & \multicolumn{2}{|c|}{ end(level 1) } & \multicolumn{2}{|c|}{ end(level 2) } & \multicolumn{2}{|c|}{ end(level 3) } & \multicolumn{2}{|c|}{ end(level 4) } \\
\hline & & horizontal & vertical & horizontal & vertical & horizontal & vertical & horizontal & vertical & horizontal & vertical \\
\hline \multirow{5}{*}{ left } & left forearm & 140 & -63 & 109 & -55 & 126 & -27 & 129 & -15 & 157 & -22 \\
\hline & left upper arm & 30 & -80 & 59 & -67 & 42 & -58 & 62 & -19 & 55 & 7 \\
\hline & left upper leg & 42 & 4 & 97 & -69 & 88 & -95 & 66 & -83 & -23 & -91 \\
\hline & left lower leg & -109 & -28 & -91 & -86 & -88 & -85 & -90 & -70 & -19 & -88 \\
\hline & left foot & 53 & -6 & 135 & -5 & 91 & -2 & 93 & 0 & 111 & -3 \\
\hline \multirow{5}{*}{ right } & right forearm & 136 & -53 & 110 & -62 & 128 & -29 & 124 & -13 & 155 & -5 \\
\hline & right upper arm & 69 & -85 & 52 & -74 & 44 & -62 & 63 & -16 & 35 & -5 \\
\hline & right upper leg & 25 & 3 & -8 & -77 & -78 & -85 & 61 & 1 & -125 & -87 \\
\hline & right lower leg & -99 & -26 & -148 & -59 & -90 & -88 & -98 & -70 & -106 & -68 \\
\hline & right foot & 54 & -4 & 6 & -23 & 80 & -7 & 68 & -9 & 49 & -29 \\
\hline trunk & flexion & \multicolumn{2}{|c|}{51} & \multicolumn{2}{|c|}{42} & \multicolumn{2}{|c|}{71} & \multicolumn{2}{|c|}{82} & \multicolumn{2}{|c|}{84} \\
\hline \multicolumn{2}{|c|}{$\begin{array}{c}\text { Average Low Back } \\
\text { Compression }\end{array}$} & \multicolumn{2}{|c|}{1090} & \multicolumn{2}{|c|}{941} & \multicolumn{2}{|c|}{769} & \multicolumn{2}{|c|}{801} & \multicolumn{2}{|c|}{719} \\
\hline
\end{tabular}


Table A1.10 Average angle and low back compression for subject 5 with manual lifting

\begin{tabular}{|c|c|c|c|c|c|c|c|c|c|c|c|}
\hline & \multirow{3}{*}{ Subject 5} & \multicolumn{10}{|c|}{ Average Angle } \\
\hline & & \multicolumn{2}{|c|}{ begin } & \multicolumn{2}{|c|}{ end(level 1) } & \multicolumn{2}{|c|}{ end(level 2) } & \multicolumn{2}{|c|}{ end(level 3) } & \multicolumn{2}{|c|}{ end(level 4) } \\
\hline & & horizontal & vertical & horizontal & vertical & horizontal & vertical & horizontal & vertical & horizontal & vertical \\
\hline \multirow{5}{*}{ left } & left forearm & 100 & -54 & 109 & -55 & 110 & -55 & 113 & -2 & 118 & 11 \\
\hline & left upper arm & -41 & -69 & 3 & -67 & 51 & -69 & 33 & -51 & 8 & -49 \\
\hline & left upper leg & 66 & -10 & 91 & -52 & 89 & -88 & 68 & -80 & -33 & -88 \\
\hline & left lower leg & -112 & -26 & -100 & -75 & -89 & -91 & -89 & -76 & 0 & -86 \\
\hline & left foot & 52 & -27 & 137 & -2 & 92 & -17 & 93 & -9 & 95 & -24 \\
\hline \multirow{5}{*}{ right } & right forearm & 99 & -71 & 94 & -65 & 102 & -57 & 124 & 3 & 109 & 6 \\
\hline & right upper arm & 0 & -67 & -11 & -63 & 29 & -76 & 35 & -45 & 11 & -45 \\
\hline & right upper leg & 66 & -13 & 52 & -68 & -4 & -80 & 11 & -86 & -100 & -87 \\
\hline & right lower leg & -111 & -25 & -150 & -56 & -95 & -21 & -84 & -75 & -98 & -86 \\
\hline & right foot & 53 & -4 & -4 & -27 & 51 & -23 & 71 & 2 & 99 & -15 \\
\hline trunk & flexion & \multicolumn{2}{|c|}{30} & \multicolumn{2}{|c|}{22} & \multicolumn{2}{|c|}{56} & \multicolumn{2}{|c|}{80} & \multicolumn{2}{|c|}{81} \\
\hline \multicolumn{2}{|c|}{$\begin{array}{c}\text { Average Low Back } \\
\text { Compression }\end{array}$} & \multicolumn{2}{|c|}{1268} & \multicolumn{2}{|c|}{1018} & \multicolumn{2}{|c|}{831} & \multicolumn{2}{|c|}{825} & \multicolumn{2}{|c|}{789} \\
\hline
\end{tabular}


Table A1.11 Average angle and low back compression for subject 6 with tool lifting

\begin{tabular}{|c|c|c|c|c|c|c|c|c|c|c|c|}
\hline & \multirow{3}{*}{ Subject 6} & \multicolumn{10}{|c|}{ Average Angle } \\
\hline & & \multicolumn{2}{|c|}{ begin } & \multicolumn{2}{|c|}{ end(level 1) } & \multicolumn{2}{|c|}{ end(level 2) } & \multicolumn{2}{|c|}{ end(level 3) } & \multicolumn{2}{|c|}{ end(level 4) } \\
\hline & & horizontal & vertical & horizontal & vertical & horizontal & vertical & horizontal & vertical & horizontal & vertical \\
\hline \multirow{5}{*}{ left } & left forearm & 124 & -53 & 103 & -68 & 128 & -28 & 134 & -17 & 149 & -26 \\
\hline & left upper arm & 60 & -79 & 70 & -72 & 42 & -60 & 64 & -16 & 53 & 13 \\
\hline & left upper leg & 34 & -3 & 88 & -78 & 74 & -95 & 82 & -79 & 8 & -88 \\
\hline & left lower leg & -115 & -26 & -81 & -82 & -95 & -87 & -87 & -76 & -9 & -87 \\
\hline & left foot & 50 & 1 & 136 & -1 & 94 & 2 & 91 & -2 & 111 & -2 \\
\hline \multirow{5}{*}{ right } & right forearm & 142 & -58 & 118 & -68 & 126 & -28 & 122 & -15 & 156 & -5 \\
\hline & right upper arm & 31 & -78 & 57 & -75 & 42 & -56 & 65 & -19 & 35 & -3 \\
\hline & right upper leg & 53 & 0 & -5 & -77 & -80 & -84 & 56 & -29 & -114 & -85 \\
\hline & right lower leg & -119 & -30 & -152 & -63 & -87 & -87 & -99 & -74 & -99 & -62 \\
\hline & right foot & 59 & -1 & -16 & -19 & 80 & -9 & 68 & -10 & 52 & -1 \\
\hline trunk & flexion & \multicolumn{2}{|c|}{61} & \multicolumn{2}{|c|}{38} & \multicolumn{2}{|c|}{70} & \multicolumn{2}{|c|}{76} & \multicolumn{2}{|c|}{84} \\
\hline & $\begin{array}{l}\text { rage Low Back } \\
\text { ompression }\end{array}$ & \multicolumn{2}{|c|}{1072} & \multicolumn{2}{|c|}{1001} & \multicolumn{2}{|c|}{726} & \multicolumn{2}{|c|}{805} & \multicolumn{2}{|c|}{644} \\
\hline
\end{tabular}


Table A1.12 Average angle and low back compression for subject 6 with manual lifting

\begin{tabular}{|c|c|c|c|c|c|c|c|c|c|c|c|}
\hline & \multirow{3}{*}{ Subject 6} & \multicolumn{10}{|c|}{ Average Angle } \\
\hline & & \multicolumn{2}{|c|}{ begin } & \multicolumn{2}{|c|}{ end(level 1) } & \multicolumn{2}{|c|}{ end(level 2) } & \multicolumn{2}{|c|}{ end(level 3) } & \multicolumn{2}{|c|}{ end(level 4) } \\
\hline & & horizontal & vertical & horizontal & vertical & horizontal & vertical & horizontal & vertical & horizontal & vertical \\
\hline \multirow{5}{*}{ left } & left forearm & 117 & -71 & 107 & -44 & 111 & -49 & 117 & 0 & 115 & 8 \\
\hline & left upper arm & -16 & -67 & 0 & -66 & 65 & -71 & 29 & -50 & 9 & -45 \\
\hline & left upper leg & 62 & -8 & 94 & -56 & 85 & -88 & 67 & -80 & -4 & -87 \\
\hline & left lower leg & -118 & -25 & -100 & -74 & -89 & -84 & -90 & -74 & -30 & -85 \\
\hline & left foot & 53 & -27 & 120 & 1 & 126 & -17 & 78 & -2 & 101 & -23 \\
\hline \multirow{5}{*}{ right } & right forearm & 117 & -74 & 87 & -57 & 109 & -59 & 129 & 4 & 107 & 9 \\
\hline & right upper arm & -41 & -72 & -9 & -66 & 13 & -76 & 32 & -39 & 13 & -46 \\
\hline & right upper leg & 64 & -11 & 39 & -72 & -16 & -81 & 23 & -84 & -94 & -90 \\
\hline & right lower leg & -107 & -25 & -146 & -56 & -104 & -14 & -92 & -79 & -89 & -89 \\
\hline & right foot & 51 & -8 & 6 & -24 & 76 & -27 & 75 & 2 & 81 & -22 \\
\hline trunk & flexion & \multicolumn{2}{|c|}{33} & \multicolumn{2}{|c|}{23} & \multicolumn{2}{|c|}{62} & \multicolumn{2}{|c|}{84} & \multicolumn{2}{|c|}{83} \\
\hline & $\begin{array}{l}\text { rage Low Back } \\
\text { ompression }\end{array}$ & \multicolumn{2}{|c|}{1266} & \multicolumn{2}{|c|}{1288} & \multicolumn{2}{|c|}{779} & \multicolumn{2}{|c|}{799} & \multicolumn{2}{|c|}{671} \\
\hline
\end{tabular}




\section{APPENDIX II}

Table A2.1 Horizontal Multiplier

Table A2.2 Vertical Multiplier

\begin{tabular}{|c|c|c|c|}
\hline H & $\bar{F}$ & $\overline{\boldsymbol{H}}$ & $\overline{H I M}$ \\
\hline & in & $\mathrm{cm}$ & \\
\hline 310 & 1.00 & $\leq 25$ & \\
\hline 11 & .81 & 28 & \\
\hline 16 & .83 & 30 & \\
\hline$\sqrt{13}$ & .77 & 32 & .78 \\
\hline 74 & .71 & 37 & \\
\hline 15 & .67 & 36 & .69 \\
\hline 16 & .63 & 38 & .66 \\
\hline & .39 & 40 & .63 \\
\hline 10 & .56 & 42 & .60 \\
\hline 8 & .55 & 4 & .57 \\
\hline 20 & 50 & 76 & .54 \\
\hline 21 & .78 & 78 & .52 \\
\hline 22 & .16 & 30 & .50 \\
\hline $2 \mathbf{3}$ & 44 & 52 & .48 \\
\hline 24 & .62 & 54 & .46 \\
\hline 25 & .40 & 35 & .45 \\
\hline 325 & .00 & 58 & .43 \\
\hline & & 60 & .42 \\
\hline & & $\sqrt{63}$ & .70 \\
\hline & & $>63$ & .00 \\
\hline
\end{tabular}

\begin{tabular}{|c|c|c|c|}
\hline$\sqrt{V}$ & $\overline{V I}$ & $\bar{V}$ & $\overline{\nabla M}$ \\
\hline in & & cm & \\
\hline & .78 & 0 & \\
\hline & .81 & 10 & 1 \\
\hline 10 & .85 & 20 & 4 \\
\hline 75 & .89 & 30 & .87 \\
\hline 20 & 93 & 40 & .90 \\
\hline 25 & .85 & 30 & 93 \\
\hline 30 & 7.00 & 60 & 6 \\
\hline 35 & .96 & 70 & .99 \\
\hline 70 & .93 & 80 & .99 \\
\hline 45 & .89 & 90 & $\$ 6$ \\
\hline 50 & .85 & 100 & .93 \\
\hline 55 & .87 & 910 & .90 \\
\hline 60 & .78 & 120 & .87 \\
\hline 65 & .74 & 130 & $8 \pi$ \\
\hline 70 & .70 & 140 & .81 \\
\hline$>70$ & 7.00 & 150 & 8 \\
\hline & & 760 & \\
\hline & & 770 & .72 \\
\hline & & 175 & \\
\hline & & $>175$ & .00 \\
\hline
\end{tabular}


Table A2.3 Distance Multiplier

\begin{tabular}{|c|c|c|c|}
\hline $\mathrm{D}$ & $\mathrm{b}$ & $\mathrm{D}$ & $\mathrm{bm}$ \\
\hline $\mathrm{n}$ & & $\mathrm{cm}$ & \\
\hline 510 & 1.00 & 525 & 1.00 \\
\hline 15 & .94 & 40 & .83 \\
\hline 20 & .91 & 55 & .80 \\
\hline 25 & .89 & 70 & .88 \\
\hline 30 & .88 & 85 & .87 \\
\hline 35 & .87 & 100 & .87 \\
\hline 40 & .87 & 115 & .86 \\
\hline 45 & .86 & 130 & .86 \\
\hline 50 & .86 & 145 & .85 \\
\hline 55 & .85 & 160 & .85 \\
\hline 60 & .85 & 175 & .85 \\
\hline 70 & .85 & $>175$ & .00 \\
\hline$>70$ & .00 & & \\
\hline
\end{tabular}

Table A2.4 Asymmetry Multiplier

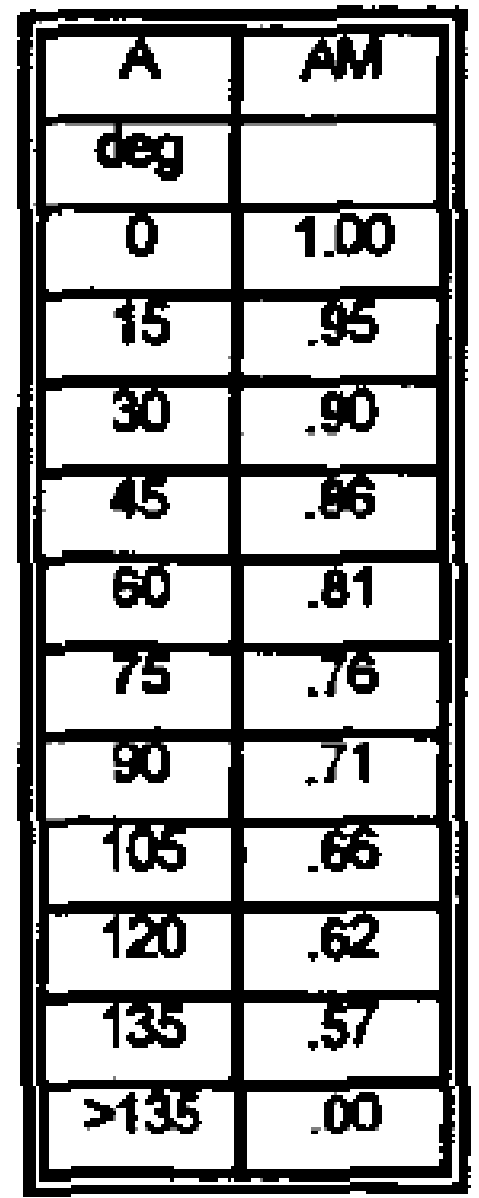


Table A2.5 Frequency Multiplier

\begin{tabular}{|c|c|c|c|c|c|c|}
\hline \multirow{3}{*}{$\underset{m}{m}$} & \multicolumn{6}{|c|}{ DURATK'N } \\
\hline & \multicolumn{2}{|c|}{$<1$ horr } & \multicolumn{2}{|c|}{192 house } & \multicolumn{2}{|c|}{$2-6$ hows } \\
\hline & $\begin{array}{l}V< \\
30 \text { in }\end{array}$ & $\begin{array}{l}V \geq \\
30 \mathrm{in}\end{array}$ & $\begin{array}{c}V_{k} \\
30 \text { in }\end{array}$ & $\begin{array}{l}v \geq \\
30 \mathrm{in}\end{array}$ & $\begin{array}{l}V< \\
30 \text { in }\end{array}$ & 30 \\
\hline$\leq 2$ & 1.00 & 3.00 & .85 & .85 & .85 & .85 \\
\hline .5 & .97 & .97 & .92 & .92 & .81 & .81 \\
\hline 1 & .99 & .94 & .88 & .88 & .75 & .75 \\
\hline 2 & .91 & .91 & .84 & .84 & .65 & .65 \\
\hline 3 & .88 & .88 & .79 & .79 & .55 & .55 \\
\hline 4 & .64 & .84 & $\sqrt{2}$ &.$\overline{2}$ & .45 & .45 \\
\hline 5 & .80 & .80 & .60 & .60 & .35 & .35 \\
\hline 6 & .75 & .75 & .50 & .50 & .27 & .27 \\
\hline 7 & $.70^{\circ}$ & .70 & .42 & .42 & .22 & 22 \\
\hline 8 & .60 & .60 & .35 & .35 & .18 & .18 \\
\hline 9 & .52 & .52 & .30 & 30 & .00 & .75 \\
\hline fo & .45 & .45 & .25 & .26 & .00 & .13 \\
\hline 71 & .41 & .41 & .00 & .23 & .00 &.$\infty$ \\
\hline 12 & .37 & .37 & .00 & 21 &.$\infty 0$ & .00 \\
\hline 73 & .00 & .34 & .00 & .00 & .0 & .00 \\
\hline 34 & .0 & .31 &.$\infty$ &.$\infty$ & .00 &.$\infty$ \\
\hline 15 & .00 & .28 & .00 & .00 & .00 & .00 \\
\hline$>15$ & .00 & .00 & .00 & .00 &.$\infty$ & .00 \\
\hline
\end{tabular}

Table A2.6 Hand-to-Container Coupling Multiplier

\begin{tabular}{|c|c|c|}
\hline $\begin{array}{c}\text { COLPLE } \\
\text { TYPE }\end{array}$ & $\begin{array}{l}C \\
\text { in } \\
\text { in }\end{array}$ & $\frac{\sqrt{30}}{\text { in }}$ \\
\hline 6000 & 1.00 & 1.00 \\
\hline FANR & .95 & 1.00 \\
\hline POOK & .90 & .90 \\
\hline
\end{tabular}


Table A2.7 The values of RWL.

\begin{tabular}{|c|cc|cc|}
\hline \multicolumn{4}{|c|}{ RWL } \\
\hline \multirow{2}{*}{} & \multicolumn{2}{|c|}{ HAND } & \multicolumn{2}{c|}{ TOOL } \\
\cline { 2 - 5 } & BEGIN & END & BEGIN & END \\
\hline $1.5 \mathrm{FT}$ & 25.39 & 14.95 & 29.82 & 17.12 \\
$2.5 \mathrm{FT}$ & 24.29 & 17.67 & 28.52 & 18.42 \\
$3.5 \mathrm{FT}$ & 24.01 & 15.89 & 28.19 & 16.39 \\
$4.5 \mathrm{FT}$ & 23.46 & 13.99 & 27.55 & 14.24 \\
\hline
\end{tabular}

Table A2.8 The values of all the six task variables for NIOSH lifting equation.

\begin{tabular}{|c|c|c|c|c|c|}
\hline & \multicolumn{2}{|c|}{ HAND } & \multicolumn{2}{|c|}{ TOOL } \\
\hline & & BEGIN & END & BEGIN & END \\
\hline \multirow{4}{*}{$\mathrm{H}$} & $1.5 \mathrm{FT}$ & 12 & 17 & 12 & 17 \\
\hline & $2.5 \mathrm{FT}$ & 12 & 16 & 12 & 14 \\
\hline & $3.5 \mathrm{FT}$ & 12 & 16 & 12 & 14 \\
\hline & $4.5 \mathrm{FT}$ & 12 & 16 & 12 & 14 \\
\hline \multirow{4}{*}{ V } & $1.5 \mathrm{FT}$ & 0 & 18 & 13 & 31 \\
\hline & $2.5 \mathrm{FT}$ & 0 & 30 & 13 & 43 \\
\hline & $3.5 \mathrm{FT}$ & 0 & 42 & 13 & 55 \\
\hline & $4.5 \mathrm{FT}$ & 0 & 54 & 13 & 67 \\
\hline \multirow{4}{*}{ D } & $1.5 \mathrm{FT}$ & 18 & 18 & 18 & 18 \\
\hline & $2.5 \mathrm{FT}$ & 30 & 30 & 30 & 30 \\
\hline & $3.5 \mathrm{FT}$ & 42 & 42 & 42 & 42 \\
\hline & $4.5 \mathrm{FT}$ & 54 & 54 & 54 & 54 \\
\hline \multirow{4}{*}{ A } & $1.5 \mathrm{FT}$ & 0 & 90 & 0 & 90 \\
\hline & $2.5 \mathrm{FT}$ & 0 & 90 & 0 & 90 \\
\hline & $3.5 \mathrm{FT}$ & 0 & 90 & 0 & 90 \\
\hline & $4.5 \mathrm{FT}$ & 0 & 90 & 0 & 90 \\
\hline \multirow{4}{*}{$\mathrm{F}$} & $1.5 \mathrm{FT}$ & 3 & 3 & 3 & 3 \\
\hline & $2.5 \mathrm{FT}$ & 3 & 3 & 3 & 3 \\
\hline & $3.5 \mathrm{FT}$ & 3 & 3 & 3 & 3 \\
\hline & $4.5 \mathrm{FT}$ & 3 & 3 & 3 & 3 \\
\hline $\mathrm{C}$ & & \multicolumn{2}{|c|}{ Fair } & \multicolumn{2}{|c|}{ Good } \\
\hline
\end{tabular}


Table A2.9 The values of all the six coefficients for NIOSH lifting equation.

\begin{tabular}{|c|c|c|c|c|c|}
\hline & \multicolumn{2}{|c|}{ HAND } & \multicolumn{2}{|c|}{ TOOL } \\
\hline & & BEGIN & END & BEGIN & END \\
\hline \multirow{4}{*}{$\mathrm{HM}$} & $1.5 \mathrm{FT}$ & 0.83 & 0.59 & 0.83 & 0.59 \\
\hline & $2.5 \mathrm{FT}$ & 0.83 & 0.63 & 0.83 & 0.73 \\
\hline & $3.5 \mathrm{FT}$ & 0.83 & 0.63 & 0.83 & 0.73 \\
\hline & $4.5 \mathrm{FT}$ & 0.83 & 0.63 & 0.83 & 0.73 \\
\hline \multirow{4}{*}{ VM } & $1.5 \mathrm{FT}$ & 0 & 18 & 13 & 31 \\
\hline & $2.5 \mathrm{FT}$ & 0 & 30 & 13 & 43 \\
\hline & $3.5 \mathrm{FT}$ & 0 & 42 & 13 & 55 \\
\hline & $4.5 \mathrm{FT}$ & 0 & 54 & 13 & 67 \\
\hline \multirow{4}{*}{ DM } & $1.5 \mathrm{FT}$ & 0.92 & 0.92 & 0.92 & 0.92 \\
\hline & $2.5 \mathrm{FT}$ & 0.88 & 0.88 & 0.88 & 0.88 \\
\hline & $3.5 \mathrm{FT}$ & 0.87 & 0.87 & 0.87 & 0.87 \\
\hline & $4.5 \mathrm{FT}$ & 0.85 & 0.85 & 0.85 & 0.85 \\
\hline \multirow{4}{*}{$\mathrm{AM}$} & $1.5 \mathrm{FT}$ & 1 & 0.71 & 1 & 0.71 \\
\hline & $2.5 \mathrm{FT}$ & 1 & 0.71 & 1 & 0.71 \\
\hline & $3.5 \mathrm{FT}$ & 1 & 0.71 & 1 & 0.71 \\
\hline & $4.5 \mathrm{FT}$ & 1 & 0.71 & 1 & 0.71 \\
\hline \multirow{4}{*}{ FM } & $1.5 \mathrm{FT}$ & 0.88 & 0.88 & 0.88 & 0.88 \\
\hline & $2.5 \mathrm{FT}$ & 0.88 & 0.88 & 0.88 & 0.88 \\
\hline & $3.5 \mathrm{FT}$ & 0.88 & 0.88 & 0.88 & 0.88 \\
\hline & $4.5 \mathrm{FT}$ & 0.88 & 0.88 & 0.88 & 0.88 \\
\hline \multirow{4}{*}{$\mathrm{CM}$} & $1.5 \mathrm{FT}$ & 0.95 & 0.95 & 1 & 1 \\
\hline & $2.5 \mathrm{FT}$ & 0.95 & 1 & 1 & 1 \\
\hline & $3.5 \mathrm{FT}$ & 0.95 & 1 & 1 & 1 \\
\hline & $4.5 \mathrm{FT}$ & 0.95 & 1 & 1 & 1 \\
\hline
\end{tabular}




\section{REFERENCES}

Ayoub, M.M., and Mital, A., Manual Materials Handling, Taylor \& Francis, London, 1989.

Bernard, B.P., "Musculoskeletal Disorders and Workplace Factors: A Critical Review of Epidemiologic Evidence for Work-Related Disorders of the Neck, Upper Extremity, and Low Back," DHHS (NIOSH) Publication No. 97 - 141. (Cincinnati, OH: U.S. Department of Health and Human Services, Public Health Service, Centers for Disease Control and Prevention, National Institute for Occupational Safety and Health), 1997.

Brinckmann, P., Biggemann, M. and Hilweg, D., "Fatigue fracture of human lumbar vertebrae," Clinical Biomechanics, Supplement 1, 1988

Buchholz, B., Paquet, V., Punnett, L., Lee, D. and Moir, S. M., "PATH: A work sampling-based approach to ergonomic job analysis for construction and other non-repetitive work," Ergonomics, 27, pp. 171-187, 1996.

Bulthuis, B. M., Begemann-Meijer, M. J. T., Binkhorst, R. A., Vink, P., Daanen, H. A. M. and Ligteringen, J., "Work load in the building industry," Proceedings of the Eleventh Congress of the International Ergonomics Association (London: Taylor and Francis), pp. 275-277, 1991.

Bureau of Labor Statistics, 2002b, "Incidence rates for nonfatal occupational injuries and illnesses involving days away from work per 10,000 full-time workers by industry and selected 
events or exposures leading to injury or illness," Table R8 2002. Available online at: http://stats.bls.gov/iif/oshwc/osh/case/ostb1275.pdf (accessed 6 January 2004).

Caldwell, L. S., Chaffin, D. B., Dukes-Bobos, F. N., Kroemer, K. H. E., Laubach, L. L., Snook, S. H. and Wasserman, D. E., "A proposed standard procedure for static muscle strength testing," American Industrial Hygiene Association Journal, 35, pp. 201-206, 1974.

Chaffin, D. B., and Park, K. S., "A longitudinal study of low back pain as associated with occupational lifting factor," American Industrial Hygiene Association Journal, 34, pp. 513-525, 1973.

Chaffin, D. B., and Andersson. G.B.J., Occupational Biomechanics, John Wiley \& Sons, New York, 1984.

D. Anton, J. C. Rosecrance, F. Gerr, L. A. Merlino and T. M. Cook, "Effect of concrete block weight and wall height on electromyographic activity and heart rate of masons," Erogonomics, vol.48, No.10, pp. 1314-133, 15 August 2005.

Davis, K. G., Marras, W. S. and Waters, T. R., "Evaluation of the spinal loading during lowering and lifting," Clinical Biomechanics, 13(3), pp. 141-152, 1997.

Daynard, D., Yassi, A., Cooper, J. E., Tate, R., Norman, R., and Wells, R., "Biomechanical analysis of peak and cumulative spinal loads during simulated patienthandling activities: a 
substudy of a randomized controlled trial to prevent lift and transfer injury of health care workers," in Ergonomics, 32, pp. 199-214, 2001.

De Looze, M. P., Visser B., Houting, I., Van Rooy, M. A. G., Van Dieen, J.H. and Toussaint, H. M., "Weight and frequency effect on spinal loading in a bricklaying task," journal of Biomechanics, 29, pp. 142-1433, 1996.

“Energy Expenditure Prediction Program ${ }^{\mathrm{TM}}$ Version 2.0," Center For Ergonomics, University of Michigan.

Ferguson, S. A., Marras, W. S. and Burr, D., "Workplace design guidelines for asymptomatic vs. lowback-injured workers," in Ergonomics, 36, pp. 85-95, 2005.

Frymoyer, J. W., Pope, M. H. and Constanza, M. C., "Epidemiological studies of low back pain," in Spine, 5, pp. 419-423, 1980.

H. F. Van Der Molen, P. P. F. M. Kuijer, P. P. W. Hopmans, A. G. Houweling, G. S. Faber, M. J. M. Hoozemans and M. H. W. Frings-Dresen, "Effect of block weight on work demands and physical workload during masonry work," in Erogonomics, vol.51, No.3, pp. 355-366, March 2008. 
Hansson, T. H., Keller, T. S. and Spengler, D. M., "Mechanical behavior of the human lumbar spine II Fatigue Strength During Dynamic Compressive Loading," Journal of Orthopaedic Research, 5, pp. 479-487, 1987.

Indiana University, Stat/Math Center, http://www.indiana.edu/ statmath/stat/minitab/win/1.html.

Jaèger, M., Luttmann, A. and Laurig, W., "Lumbar load during one-handed bricklaying," International Journal of Industrial Ergonomics, 8, pp. 261-277, 1991.

Johnson, S. and Lewis, D., “A psychophysical study of two-person manual materials handling tasks," in Proceedings of the Human Factors Society 33rd Annual Meeting, (Santa Monica: Human Factors Society), pp. 651-653, 1989.

Karwowski, W. and Mital, "Isometric and Isokinetic Testing of Lifting Strength of Males in Teamwork", in Ergonomics, 29, pp. 869-878. 1986.

Karwowski, W., "Maximum load lifting capacity of males and females in teamwork," in Proceedings of the Human Factors Society 32nd Annual Meeting (Santa Monica: Human Factors Society), pp. 680-682, 1988.

Kumar, S., "Cumulative load as a risk factor for back pain,” in Spine, 15, pp. 1311-1316, 1990. [3] W. S. Marras*, K. G. Davis, B. C. Kirking and K. P. Granata, "Spine loading and trunk kinematics during team lifting," in Erogonomics, vol.42, No.10, pp. 1258-1273, 1999. 
Marras, W. S., Lavender, S. A., Leurgans, S. E., Fathallah, F. A., Ferguson, S. A., Allread, W. G. and Rajulu, S. L., "Biomechanical risk factors for occupationally related low back disorders," Ergonomics, 38, pp. 337-410, 1995. [6] Sturmer, T., Luessenhoop, S., Neth, A., Soyka, M., Karmaus, W., Toussaint, R., Liebs, T. R. and Rehder, U., "Construction work and low back disorder," Spine, 22, pp. 2558-2563, 1997.

Liu, Y. K. Nijus, G., Buckwalter, J. and Wakano, K., "Fatigue Resource of Lumbar Intervertebral Joints Under Axial Cyclic Loading,” Spine, 8, 857 - 865, 1983.

McAtamney, L., Corlett, E. N., "RULA: a survey method for the investigation of work-related upper limb disorders," Applied Ergonomics, 24, pp. 91-99, 1993.

Mcgill, S. M., "Estimation of force and extensor moment contributions of the disc and ligaments at L4/L5," in Spine, 13, pp. 1395-1402, 1988.

Mcgill, S. M., "The biomechanics of low back injury: implications on current practice in industry and the clinic," journal of Biomechanics, 30, pp. 465-475, 1997. [11] Sharp, M., Rice, V., Nindl, B. C. and Mello, P., "Maximum acceptable load for lifting and carrying in two-person teams," in Proceedings of the Human Factors and Ergonomics 39th Annual Meeting (Santa Monica: Human Factors Society), pp.640-644, 1995. 
Ortengren, R., Cederqvist, T., Lindberg, M., and Magnusson, B., "Workload in lower arm and shoulder when using manual and powered screwdrivers at different working heights," in International Journal of Industrial Ergonomics, 8, pp225-235, 1991.

Schneider, S. P., "Musculoskeletal injuries in construction: a review of the literature," in Occupational and Environmental Hygiene, 16, pp. 1056-1064, 2001.

Van Der Beek, A. J., Mathiassen, S. E., Windhorst, J. and Burdorf, A., "An evaluation of methods assessing the physical demands of manual lifting in scaffolding," in Ergonomics, 36, pp. 213-222, 2005.

Van Der Molen, H. F., Grouwstra, R., Kuijer, P. P. F. M., Sluiter, J. K. and Frings-Dresen, M. H. W., "Efficacy of adjusting working height and mechanizing of transport on physical work demands and local discomfort in construction work," in Ergonomics, 47, pp. 772-783, 2004.

Vincent, M ., Buckle, p., and Stubbs, D., "Stature changes in and psycho-physical ratings associated with repetitive lifting," in Musculo-skeletal Disorders at Work, pp103-107, 1987.

Waters, T, R., Putz-Anderson, V., Grag, A. and Fine, L. J., "Revised NIOSH equation for the design and evaluation of manual lifting tasks," in Ergonomics, 36, pp. 749-776, 1993.

Waters, T., Yeung, S., Genaidy, A., Callaghan, J., Barriera-Viruet, H., Abdallah, S. and Kumar, S., "Cumulative spinal loading exposure methods for manual material handing tasks. Part2: 
methodological issues and applicability for use in epidemiological studies," in Theoretical Issues in Ergonomic Science, 7, pp 131-148, 2006.

3DSSPP, Background,

http://www.engin.umich.edu/dept/ioe/3DSSPP/background.html.

John $\mathrm{H}$. 